Article

\title{
Examining the Journey of a Pay-as-You-Go Solar Home System Customer: A Case Study of Rwanda
}

\author{
Vivien Kizilcec $^{1}\left(\mathbb{D}\right.$, Priti Parikh ${ }^{1, *}$ a and Iwona Bisaga ${ }^{1,2}(\mathbb{D}$ \\ 1 Engineering for International Development Research Centre, \\ The Bartlett School of Construction and Project Management, University College London, \\ London WC1H 0NN, UK; vivien.kizilcec.17@ucl.ac.uk (V.K.); i.m.bisaga@lboro.ac.uk (I.B.) \\ 2 Department of Geography and Environment, Loughborough University, Loughborough LE11 3TU, UK \\ * Correspondence: priti.parikh@ucl.ac.uk
}

check for updates

Citation: Kizilcec, V.; Parikh, P.;

Bisaga, I. Examining the Journey of a Pay-as-You-Go Solar Home System Customer: A Case Study of Rwanda. Energies 2021, 14, 330. https:// doi.org/10.3390/en14020330

Received: 10 November 2020 Accepted: 5 January 2021 Published: 8 January 2021

Publisher's Note: MDPI stays neutral with regard to jurisdictional clai$\mathrm{ms}$ in published maps and institutional affiliations.

Copyright: $\odot 2021$ by the authors. Licensee MDPI, Basel, Switzerland. This article is an open access article distributed under the terms and conditions of the Creative Commons Attribution (CC BY) license (https:// creativecommons.org/licenses/by/ $4.0 /)$.

\begin{abstract}
Solar home systems (SHSs) are successfully addressing energy access deficits across the globe, particularly when combined with pay-as-you-go (PAYG) payment models, allowing households to pay for energy services in small instalments. To increase energy access, it is vital to understand the PAYG SHS customer journey in depth. To aid this, the paper presents unique data from active customers, consisting of structured interviews $(n=100)$ and two focus groups $(n=24)$ across two districts in Rwanda. These results are presented under a novel customer journey framework, which describes all the individual stages a customer might experience, including awareness and understanding, purchase, usage, upgrade, recommendation and retaining or switching energy source. The paper reveals that the customer journey is non-linear and cyclical in nature, acknowledging that a household operates in a social network within which they could influence or be influenced by others. It also highlights the growing importance of SHS recommendations in raising awareness of SHSs, pointing to the shifts in the off-grid energy market environment where customer awareness no longer appears to be a main adoption barrier.
\end{abstract}

Keywords: solar home systems (SHS); framework; pay-as-you-go; customer journey

\section{Introduction}

Research on energy access and consumption in the developing world is a growing field, particularly with the inclusion of energy access within the Sustainable Development Goals [1]. Increasing energy access is an urgent priority; in 2018 there were still 860 million people around the world that lacked access to electricity, with 600 million of them living in sub-Saharan Africa [2]. Between 2014 and 2018, the most progress in electrifying sub-Saharan Africa was made in East Africa, particularly Tanzania, Kenya and Ethiopia, accounting for more than $50 \%$ of the new electrification, which was achieved through a combination of grid and off-grid solutions, such as solar home systems (SHSs) [3]. A SHS consists of a solar panel, which charges a battery that, depending on its capacity, can power appliances such as light bulbs and televisions. SHS capacities typically range from 11 to 300 watts. Since 2010, more than 30 million SHSs were sold globally, with sales volumes increasing year on year [4]. This growth stems from households' increasing demand for appliances requiring higher energy capacity systems [4].

This market has been partly unlocked through companies' use of innovative pay-asyou-go (PAYG) models, allowing customers to pay for their SHSs in instalments over a period of time, usually from six months to three years [4]. Payments are mostly through mobile money, although some companies accept cash or offer scratch cards. These PAYG schemes are expected to help 310 million people afford larger capacity SHSs [4]. To increase energy access amongst these households, their adoption determinants and usage expectations should be understood. The authors therefore introduce a novel framework that examines the entire PAYG SHS customer journey in detail, from pre-to post-adoption. The framework 
consists of seven steps: awareness and understanding of SHSs, purchase, usage, upgrade, recommendation, switching energy source and retaining the SHS. Each of these steps is affected by individual household characteristics (e.g., education level, household size) and external factors (i.e., political, economic, social, technological) [5]. This framework is utilised to frame the existing literature and the results of a Rwandan case study, consisting of structured interviews and focus groups (FGs) with PAYG SHS customers.

\section{Literature Review}

\subsection{Theoretical Background}

This study examines the customer journey of PAYG SHS customers. A customer journey is a common topic in the service management and marketing disciplines and describes the "processual and experiential aspects of service processes as seen from the customer's viewpoint" [6]. They are usually structured around steps that customers complete over time, although not necessarily linearly. The overall journey comprises pre-purchase, purchase and post-purchase stages, where each section contains multiple touchpoints that may vary by industry [7]. The pre-purchase stage in product adoption can include gaining awareness and understanding of the product, brand recognition, considering different companies and potentially receiving a word-of-mouth recommendation. The purchase stage involves choosing between different product varieties, deciding on where to purchase it and the payment method. The post-purchase phase consists of using the technology, potentially buying additional products-thereby strengthening the loyalty between the customer and company-and providing word-of-mouth recommendations [7]. Moreover, the user or company can cancel the agreement if in breach, enabling the customers to switch to a competitor or utilise a different product at any time. Relevant literature includes the examination of the solar photovoltaics customer adoption journey by Sinitskaya et al. [8], who outlined the following steps: awareness, contact, meet, review, install and debrief. They provide an insightful overview of how homeowners and installers interconnect in this journey. It is worth noting, however, that there are divergences to the experiences of off-grid solar consumers in a developing country context, where the meeting and reviewing steps, for instance, likely play a smaller role. Ortbal [9] presents a journey map, consisting of awareness, information gathering, decision-making, purchase and after-sales, which was utilised to examine a case study of farmers in sub-Saharan Africa. The authors added useful additional trackers including pain-points and the stakeholder's feelings within each step. However, this journey was deemed not specific enough in the post-purchase stage to describe the off-grid energy experience. Within the literature, the authors found no framework that specifically covered the customer journey of PAYG SHS users, a gap that this paper addresses.

\subsection{Influencing Factors}

The PAYG SHS customer journey is affected by external factors and individual characteristics. The external influences can be categorised by the PEST framework, which covers the following macro-level influencing factors: political, economic, social and technological [10]. In the context of the PAYG SHS customer journey, the policy environment is of critical importance. Many sub-Saharan African countries face challenges associated with high grid extension costs, especially in remote rural settings. Therefore, governments often promote off-grid technologies, such as SHSs, through specific policies that support off-grid companies and can lower end-user prices [11].

Economic influences include a country's unemployment rate, which may negatively impact the SHS purchasing decision and the SHS market's competitiveness. Proximity to SHS vendors can increase adoption likelihood [12]. However, some households have limited access to PAYG SHS companies and are unable to benefit from a competitive environment.

Social external factors include cultural trends and attitudes towards adopting new technologies within a society. Moreover, the compatibility of available SHS business models with households' needs may impact the SHS journey, especially towards its end. The most 
common PAYG SHS business models are rent-to-own and fee-for-service. The rent-to-own model requires households to pay regular fees for a given time period, normally between one and three years, after which they own the SHS and appliances and may use the system at no further cost [13]. It usually renders households responsible for maintaining their system. For many, this is a burden if repair services are unavailable or too costly. Households might then switch back to previous energy sources despite having paid off the system, resulting in a negative SHS perception [14]. In comparison, the fee-for-service model consists of continued payments for energy usage, without owning the SHS [13]. These payments ensure SHS repairs when issues arise. Whilst this approach reduces the burden of self-repair, households pay for longer periods of time, potentially indefinitely, which may be a deterrent.

Technological factors that influence the customer journey include the extent of mobile phone ownership and particularly mobile money payments, which many PAYG SHS companies choose over cash payments.

The individual characteristics affecting SHS customers' journey in sub-Saharan Africa vary widely. A larger household size, for instance, can increase the SHS adoption probability, because the lighting need is likely to be greater [15-17]. Income plays a role; higher income households are more likely to purchase PAYG SHSs, which often require a high upfront down payment, although the size of this effect varies [15-20]. Moreover, regular income streams through formal employment are more conducive to PAYG SHS adoption, due to the regular monthly payments required [21]. Higher educational attainment by the household head is also linked with modern fuel use, where solar adoption is associated with medium education levels $[16,20]$. However, not all studies found evidence of this effect $[14,15]$. Finally, living in rural as opposed to urban areas increases the solar adoption likelihood, partly due to lower grid access $[16,21]$.

\subsection{Awareness, Understanding and Recommendation}

Raising awareness of SHSs is a key factor in increasing SHS diffusion. A lack of understanding, particularly of SHS benefits, results in lower uptake, especially when households weigh SHS benefits versus costs [22]. The levels of SHS awareness and understanding vary significantly by location, depending on the existing SHS penetration and the prevalence of awareness raising activities $[15,23,24]$. Households may become aware of SHSs through awareness campaigns, public demonstrations, company advertisements, sales agents and word-of-mouth recommendations [13,24-29]. SHS awareness campaigns, usually run by the government, inform households and endorse the technology [30]. SHS companies using public spaces for promotional events to demonstrate and explain the system benefits may raise awareness and improve sales, particularly in rural areas [13,31]. To increase awareness, local sales agents are deployed by SHS companies to demonstrate and sell SHSs through door-to-door marketing [13]. The sales agent approach offers a direct purchasing route. However, sales agents are reluctant to share information that reduces the sale likelihood, potentially resulting in customers being unaware of vital details, risking future SHS dissatisfaction [32]. Social networks also play an important role in awareness raising. Wordof-mouth endorsements from friends, family members and neighbours allows households to understand the benefits and costs of SHSs and can significantly raise adoption rates, particularly in rural areas $[13,25,28]$. If customers are satisfied with their SHS, they will likely recommend it; one study found that $96 \%$ of customers had done so [33]. However, word-of-mouth recommendations can also discourage adoption, especially if the information shared is not accurate [29]. SHS customers who were recommended the system had a good payment record in one study, although they were likelier to be low-energy users and less likely to upgrade [34]. More research on the effectiveness of customer referrals as a key SHS adoption determinant is needed. 


\subsection{Purchase and Usage}

SHSs are usually purchased at a shop, via a call centre or through sales agents. PAYG SHS companies require a down payment before SHS installation, after which the customer chooses how much to pay on a regular basis (e.g., weekly) to receive energy services, although some companies require a minimum amount [35]. Factors influencing households' purchase decisions include price, lighting hours and quality, educational improvements, health benefits and appliance aspirations. Gaining longer and better-quality lighting hours compared to previous lighting sources (e.g., kerosene lamps) is a common determinant $[14,33,36]$. Lighting access is also attributed to improvements in children's education due to increased study hours $[19,33,37]$. Moreover, educational benefits can be derived from information access through radios and televisions [37,38]. SHS-related health benefits include a reduction in respiratory diseases and lower morbidity rates and are thus powerful purchasing reasons $[19,33,36,39]$. SHS adoption is accompanied by the addition of new appliances, such as televisions and radios and the ability to extend the usage of existing devices, such as mobile phones. Charging phones at home is among the key purchase incentives [14,33]. Televisions and radios offer entertainment and can enhance social networks in neighbourhoods [39]. One study discovered that $86 \%$ of SHS customers owning a television watched it daily, whilst mobile phone usage increased for $89 \%$ of households after adoption [33].

\subsection{Upgrading, Retaining and Switching SHS}

After utilising their SHS, customers have three pathways, which are retaining their SHS, upgrading or switching to other energy sources. Retention is strongly linked to a household's SHS satisfaction, which can change throughout their customer journey due to usage hours after nightfall and after-sales services, for instance. Running out of SHS battery can lead to dissatisfaction and occurs if households utilise the system in non-optimal ways, such as overloading appliances [14]. Customer satisfaction and retention is also linked to good aftersales services, especially maintenance, offered through companies' warranty schemes [40-42].

To increase their SHS satisfaction, customers can upgrade by adding appliances to their original SHS package either during the existing payment plan, resulting in higher fees, or after payment completion by extending the payment period $[43,44]$. The upgrade decision can be challenging because customers consider the trade-offs between future income streams and the benefits of using additional appliances. Most households express a desire for additional appliances $[45,46]$. Similar to sign-up reasons, more lights and the ability to watch television are among the top upgrade reasons, with televisions being the most desired upgrade $[14,33,47]$. However, thus far, the uptake evidence is mixed; Opiyo [48] observed many upgrades, which contrasted findings by Bisaga and Parikh [49]. Households may not upgrade due to the higher payments required or because their SHS and appliances sufficiently cover their needs [33]. The added household value decreases with every additional appliance purchased, as they move out of energy poverty towards improving their quality of life [50].

Switching energy source can be a voluntary process due to SHS dissatisfaction or involuntary, because many PAYG SHS companies repossess a customer's SHS if they default on their payments. Common repossession reasons include a lack of financial capacity and a broken or stolen SHS [31]. Households may then be forced to switch to their previous energy sources (e.g., kerosene lamps), despite offering lower lighting satisfaction [51]. Customers may also transition to other SHS providers until they find a satisfactory supplier, which could become more prevalent as more SHS companies emerge. One study discovered that $28 \%$ of SHS customers had used a solar product beforehand [33]. Another energy source which households switch to is grid electricity, which offers the opportunity to use more appliances for longer hours and potentially motivates the purchase of larger appliances, such as fridges, although the cost, unreliable connection and electrocution fears can be a deterrent $[14,28,52,53]$. 


\subsection{Research Gap}

As evidenced in the literature review, there are studies examining one or more of the customer journey steps. However, to date there has been no published research on the entire pre-to post-purchase experience from a user's perspective. This paper fills this gap through a case study involving active PAYG SHS customers in Rwanda. This study aims to answer three key questions. Firstly, how do customers become aware and purchase their PAYG SHSs? Secondly, what are households' purchasing reasons and what do they utilise their SHS for? Thirdly, what are PAYG SHS customers' upgrade, retention and switching preferences? This holistic approach and the case study's findings improve the understanding of SHS users' experience, which can further inform the off-grid solar providers' product and service design, as well as impact national policies where off-grid solar solutions have been incorporated into the national electrification strategies. This is necessary to ensure the sustainability of such solutions.

\section{Materials and Methods}

\subsection{Framework}

A PAYG SHS customer journey framework was developed by the authors to understand the customer journey through a practical lens, which is important for both companies and researchers. For a SHS company, an increased understanding allows them to determine where improvements could be made to enrich the customer experience and increase customer loyalty [54]. Researchers need such frameworks to identify and address gaps in knowledge to support a dynamic and evolving industry. The authors build on the customer journey structure developed by Lemon and Verhoef [7], consisting of pre-purchase, purchase and post-purchase phases. Their specific steps include need recognition, consideration, search, choice, ordering, payment, consumption, usage, engagement and service requests [7]. These were adjusted for the case of PAYG SHSs and a broader view was applied, providing greater leeway for future case studies to fit into this framework. This resulted in seven steps, of which some are optional, consisting of: awareness and understanding of SHSs, purchase, usage, upgrade, recommendation, retaining the SHS and switching energy source (Figure 1). This framework acknowledges that customer journeys can differ in length and in the steps taken, highlighting the non-linear nature of the experience. For example, households may begin their journey by becoming aware of SHSs or by receiving a SHS recommendation. Moreover, customers may switch from their previous energy sources (e.g., kerosene) when they purchase a SHS or start/continue energy stacking, depending on their previous sources. The framework fills a gap in conceptualising the average PAYG SHS journey and enables insights to be categorised into key areas.

\subsection{Case Study}

The authors built the customer journey framework based on the case study of Bboxx customers, although it pertains to all PAYG SHS customers. Bboxx design and manufacture smart SHSs, which are equipped with a microchip enabling the collection of telemetry data from the systems, showing customers' energy consumption in real time [55]. The company utilises a hybrid fee-for-service and rent-to-own business model. Customers pay for their SHS and chosen appliances for three years, after which they own the appliances but not the solar panel and battery, paying an energy service fee for continued electricity usage. Throughout the journey, customers complete payments through a PAYG method and upgrade to additional appliances. 


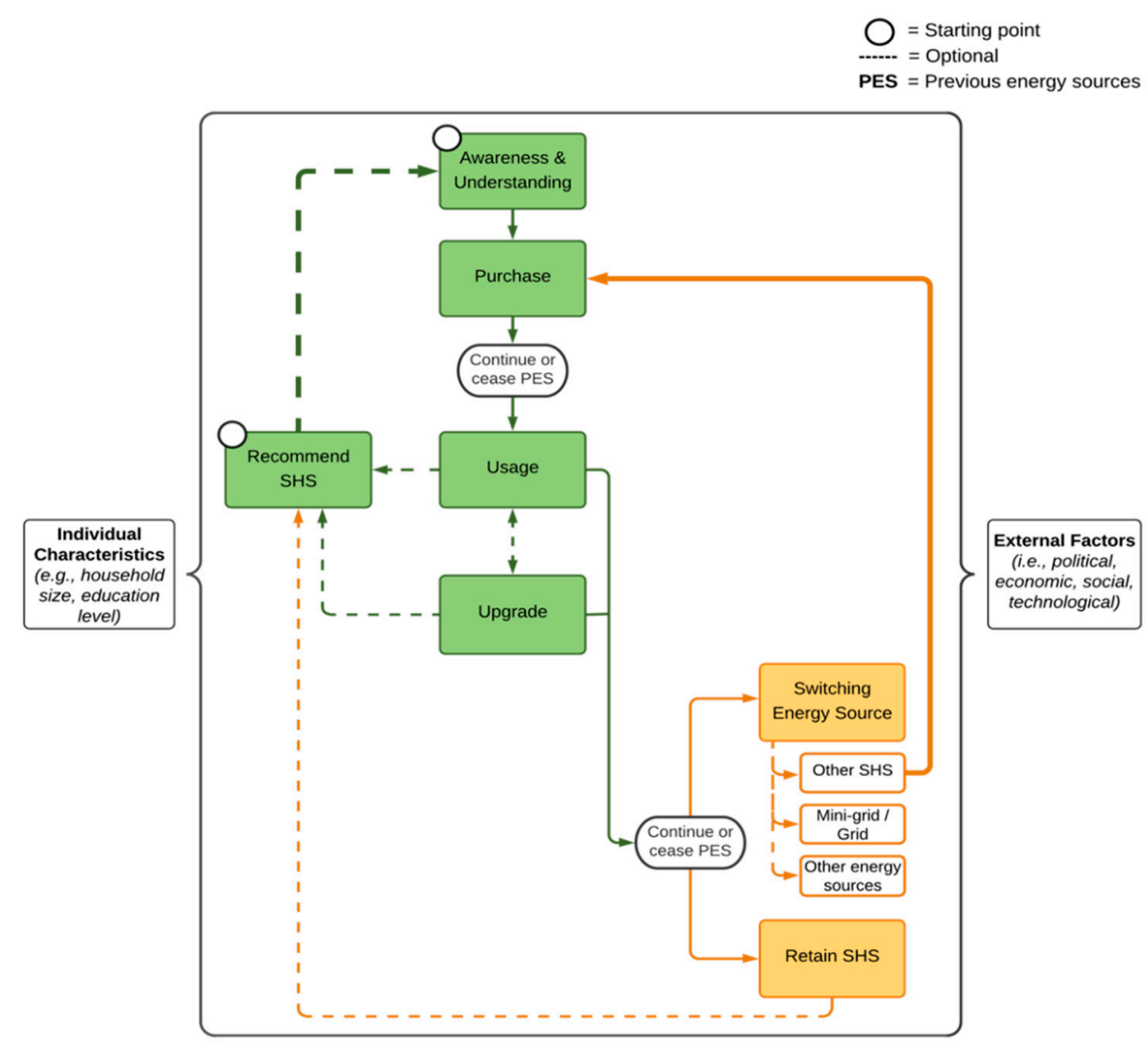

Figure 1. Pay-as-you-go solar home system (PAYG SHS) customer journey framework.

Rwanda was chosen as the study location for several reasons. Firstly, its population still has a low electricity access rate of 53\% [56]. Secondly, Rwanda is committed to achieving universal electrification by 2030 through a mixture of electricity grid and offgrid connections, which has contributed to their electricity access rate rising by $27 \%$ from 2015 [56,57]. Finally, Bboxx started their operations in Rwanda and thus constitutes their largest customer base, providing the authors an opportunity to test the framework on a substantial pool of active customers. The Eastern Province of Rwanda was studied because it is the most populous province with over 2.5 million people and $92.8 \%$ of the region is rural, where rural electrification rates are lower than their urban counterparts [58]. The province's population density differs greatly depending on the district (Figure 2). This study was focused on examining how this affects SHS recommendations and thus two districts with contrasting population densities were selected.

The two districts of Bugesera and Kayonza were chosen, which are similar in population size and Bboxx customer numbers (Table 1). Bugesera has a higher population density by a factor of 1.6 compared to Kayonza, which is larger in area size. Within these districts, the four sectors of Nyamata, Juru, Murundi and Mwiri were examined, because they contained the highest number of Bboxx customers within the respective districts and had contrasting population densities. 


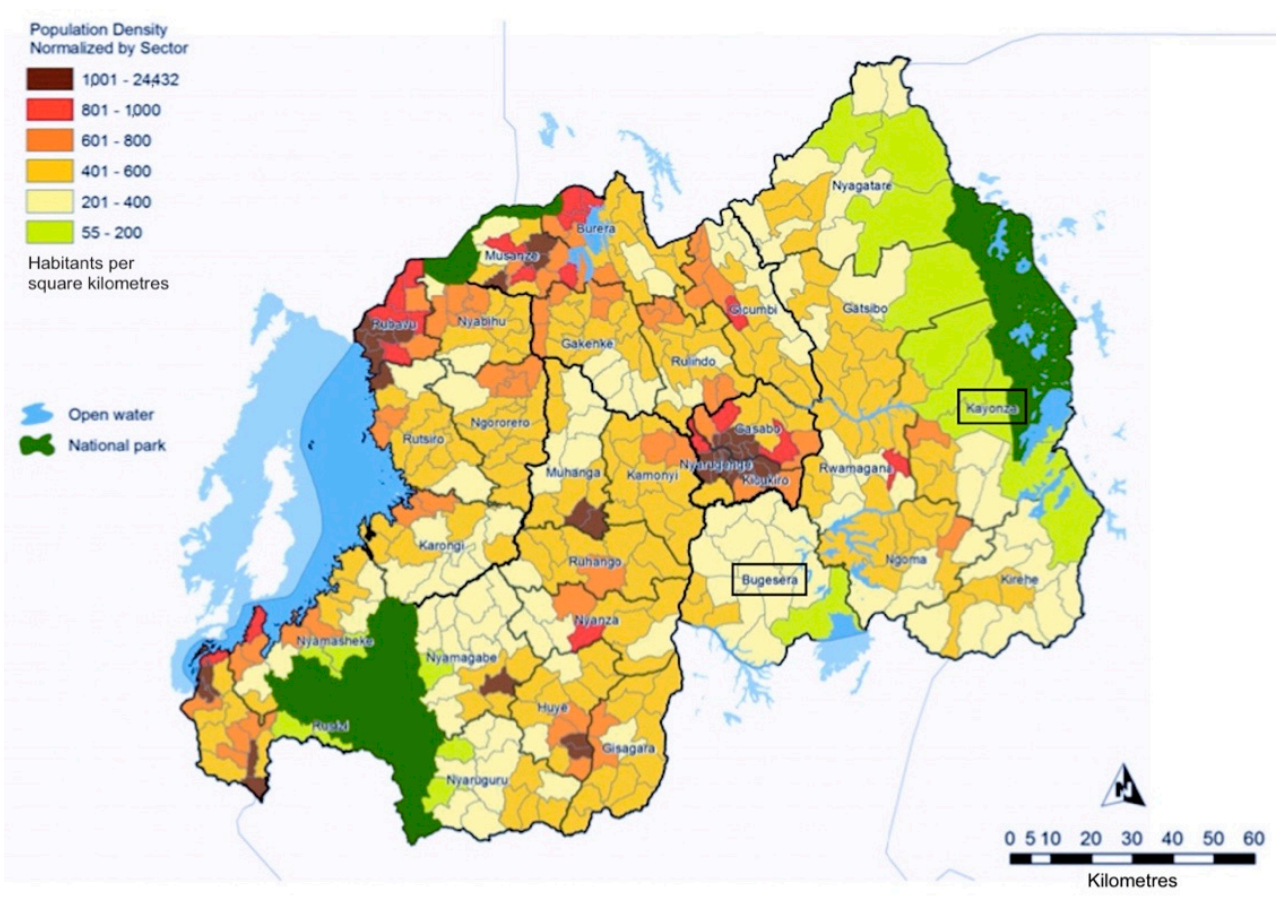

Figure 2. Population density normalized to sector (adapted from [59]).

Table 1. Bboxx customers, population and population density by sector (adapted from [60]).

\begin{tabular}{ccccc}
\hline District & Sector & Bboxx Customers & Population & $\begin{array}{c}\text { Population Density } \\
\text { (Inhabitants/(km } \mathbf{~}^{\mathbf{}} \text { ) }\end{array}$ \\
\hline \multirow{3}{*}{ Bugesera } & All sectors & 2260 & 361,914 & 280 \\
& Nyamata & 526 & 34,922 & 368 \\
& Juru & 494 & 23,673 & 291 \\
\hline \multirow{3}{*}{ Kayonza } & All sectors & 2737 & 344,157 & 178 \\
& Murundi & 399 & 26,042 & 73 \\
& Mwiri & 448 & 22,933 & 45 \\
\hline
\end{tabular}

\subsection{Research Methods}

\subsubsection{Conceptualisation}

A mixed methods approach was adopted in this study, consisting of structured interviews and FGs. A structured interview involves asking participants predetermined questions in a set order, thereby making their answers comparable and allowing generalisations to be made about the sample. However, this prohibits the interviewer asking specific follow up questions and delving deeper into the context. FGs were therefore used to supplement the interviews, allowing participants to explore perceptions about their customer journey in depth, not constrained by fixed responses. Therefore, each method added value in uncovering new information. The interview utilised binary and multiple answer multiple choice questions, alongside rating scale, Likert scale, ranking and open-ended questions to generate a rich evidence base (Appendix A).

\subsubsection{Logistics}

FGs were conducted in the local language, Kinyarwanda, in both Kayonza and Bugesera with 10 and 12 Bboxx customers participating, respectively (Appendix B). In total, 100 customers were surveyed through structured face-to-face $(n=50)$ and telephone $(n=50)$ interviews. The interview participant selection criteria included being a Bboxx customer for a minimum of three months to ensure sufficient SHS experience and being within 18 and 80 years old. Stratified and systematic sampling was utilised to ensure a more even 
split between sectors and genders-most registered customers are male, which reduced the likelihood of female participants who are often the main SHS users (Table 2) [14,61]. Using a confidence level of $95 \%$, a sample of 100 participants out of the Bboxx customer base of 1867 across the four sectors delivered a confidence interval of 9.5. Using NVivo software, the FG discussion transcripts were coded into specific themes and relevant quotes were extracted to underscore the structured interview data. The interviews were analysed in Python 3.7., where the responses to open-ended questions were coded by theme. For the closed-ended question analysis, the data was divided into the following categories: district, age group, income bracket, gender and months as Bboxx customer, each consisting of two groups, respectively. The binary multiple-choice responses were tested for each of these groups in turn using the Fisher's exact test (FET) to check whether there was a significant difference between them, necessitating a $p$-value below 0.05. A Mann-Whitney $\mathrm{U}$ test (MWW) was utilised on ranking and Likert scale answers to test whether the distributions of two groups were different. The remaining closed-ended answers were examined through exploratory data analysis.

Table 2. Number of in-person and telephone interviews.

\begin{tabular}{ccccc}
\hline District & Sector & Gender & In-Person Interviews & Telephone Interviews \\
\hline \multirow{4}{*}{ Bugesera } & \multirow{2}{*}{ Nyamata } & Female & 6 & 6 \\
& & Male & 6 & 8 \\
& \multirow{2}{*}{ Juru } & Female & 7 & 6 \\
& & Male & 6 & 6 \\
\hline \multirow{3}{*}{ Kayonza } & \multirow{3}{*}{ Murundi } & Female & 6 & 7 \\
& \multirow{3}{*}{ Mwiri } & Male & 7 & 5 \\
& & Female & 5 & 4 \\
& & Male & 7 & 8 \\
\hline
\end{tabular}

Ethical approval for this study was granted by the University College London (UCL) Research Ethics Committee [13937/001] and University of Rwanda and all respondents signed an informed consent form before participating.

\subsection{Limitations}

The study consisted of a small sample of the Bboxx customer base, resulting in a high confidence interval. This is therefore a preliminary study, because the findings are not generalisable to the entire PAYG SHS customer base in Rwanda. Despite this, the paper offers valuable findings about SHS adopters. FGs and interviews were conducted in Kinyarwanda and then translated to English, which may result in information lost in translation or mistranslated. However, the transcripts were independently checked by two people to mitigate those risks. Obtaining data on sensitive issues, such as household income, is challenging [62]. To circumvent issues, respondents selected an income bracket, potentially leading to a higher and more truthful response rate. However, respondents can be unaware of the entire household income. Self-reported data may be imprecise if customers believe they will be rewarded for particular answers.

\section{Results and Discussion}

\subsection{Influencing Factors}

The PAYG SHS customer journey is influenced by both external factors and individual characteristics. As outlined in Section 2.2, the PEST analysis framework is utilised to discuss political, economic, social and technological external forces. A political factor in this case is Rwanda's goal of complete electrification by 2024 through a mix of grid connections (52\%) and off-grid solutions (48\%) [57]. The government is thus fostering off-grid technologies, such as SHSs, through import duty and value-added tax exemptions [11]. Moreover, the country has been divided into areas for electricity grid, mini-grid and SHS expansion to boost 
effectiveness and minimise overlap between these electrification options [63]. This impacts residents' choices, potentially restricting households that prefer a grid connection. However, households are able to adopt off-grid solar products in designated grid areas, even if they are already connected to the grid. A positive correlation between grid connected households and SHS purchase was observed in neighbouring Tanzania [15]. An economic factor is Rwanda's unemployment rate, which constituted $15.2 \%$ of the population in 2019, impacting the disposable income of households and thus their likelihood to access SHSs [64]. A social factor is Rwanda's young demographic, with only $22 \%$ of the population over 35 years old, potentially influencing the willingness to purchase SHSs [65]. Moreover, a socio-cultural factor is becoming accustomed to utilising the SHS and appliances, which depends on the technological literacy of Rwandan households. A technological factor is the widespread use of mobile phones, where 78\% of the Rwandan population were active SIM card users in 2020 [66]. In 2017, the majority of mobile phone users subscribed to mobile money services, making PAYG SHS adoption easier, as most households are accustomed to this mode of payment often required by SHS companies [67].

Individual characteristics influencing the customer journey include gender, age, education, income, household occupants, house characteristics and duration as a SHS customer (Table 3). The majority of respondents (87\%) attended school, although $54 \%$ did not complete their specified education level. This does not highlight a strong association between education and SHS usage, with most people only attending primary education. Respondents under the age of 40 were more likely to have attended school, potentially highlighting a greater emphasis being placed on education in recent years (FET, $p$-value: $0.04)$. An almost even split was observed between low-income households, earning under 20,000 Rwandan Francs (RWF) in the previous month (roughly USD 20) and higher income households earning RWF 20,000 or more (Table 3). Most customers (64\%) identified as farmers, whilst the rest could be split into drivers, people working in the sales sector, labourers, teachers and entrepreneurs. Occupation determines the volatility of income streams and only $28 \%$ of participants reported having a stable monthly household income. This impacts both their energy usage and upgrade likelihood. Household size can also impact SHS adoption, where the benefits of electrification increase for larger households [15]. In this case, the average household size was five, as was the average room number, including bathrooms and kitchens. The number of rooms signifies the electrification level needed; smaller houses likely require fewer bulbs. Lastly, participants were split into four groups based on their time with Bboxx, where the largest group consisted of new customers (3-12 months). Time as a customer may impact their perceptions of the PAYG solar services, providing an insight into the differences between new and seasoned customers.

\subsection{Awareness and Understanding}

\subsubsection{SHS Awareness}

Most respondents (68\%) first heard about SHSs three or more years ago. Customers who heard about SHSs less than four years ago $(60 \%)$ were more likely to have received a recommendation from another SHS user, potentially reflecting the rise in overall SHS adoption rates (FET, $p$-value: 0.0001) (Figure 3). After becoming aware, respondents without a previous SHS $(n=63)$ waited on average 15 months before signing up for a Bboxx SHS. This shows that factors apart from awareness hinder SHS adoption in Rwanda, contrary to previous studies that cited awareness as a key barrier [68,69]. Instead, other hurdles, such as affordability, might play a more prominent role [70,71]. However, future research should examine further causes for this sign-up gap. 
Table 3. Participant's influencing individual characteristics.

\begin{tabular}{ccc}
\hline Influencing Individual Characteristics & Responses & Percent (\%) \\
\hline Gender $(n=100)$ & Male & 53 \\
Age $(n=100)$ & Female & 47 \\
\hline \multirow{2}{*}{ Education level $(n=100)$} & $18-39$ years & 52 \\
& Above 39 years & 48 \\
\hline Household income in previous month & No education & 13 \\
$(n=98)$ & Less than RWF 20,000 ( USD 20) & 51 \\
& Attended primary education & 31 \\
\multirow{2}{*}{ Household occupants in last year $(n=100)$} & Attended university & 51 \\
& $1-5$ occupants & 49 \\
\hline \multirow{2}{*}{ Number of rooms $(n=100)$} & Above 5 occupants & 56 \\
& $2-4$ rooms & 44 \\
\hline \multirow{2}{*}{ Months as Bboxx customer $(n=100)$} & $5-7$ rooms & 41 \\
& $8-10+$ rooms & 48 \\
& $3-12$ months & 11 \\
\hline
\end{tabular}

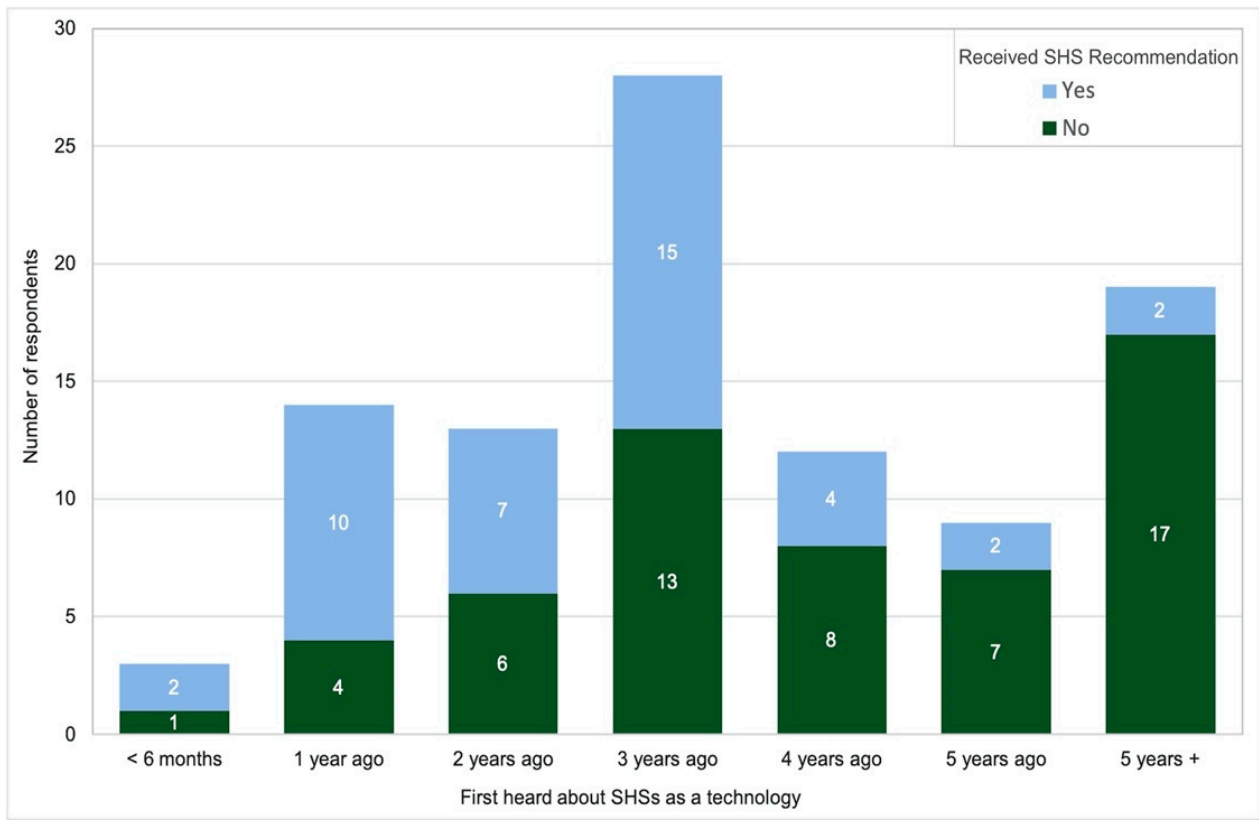

Figure 3. Respondents who first heard about SHSs, split by receiving a SHS recommendation.

\subsubsection{Received SHS Recommendation}

Almost half of participants (44\%) were recommended a SHS by someone who owned one. However, this varied widely within sectors, where Nyamata participants were more likely to receive a recommendation $(n=20)$ than their Juru counterparts $(n=5)$. This contradicts the assumption that households in more densely populated areas are always more likely to recommend SHSs. Particularly, as both Nyamata and Juru are more densely populated than the two Kayonza districts (Table 1). Social factors within each sector could influence the varying recommendation rates, with density having an inconclusive impact on recommendations. The SHS recommenders for the study's participants can be grouped into neighbours $(72 \%)$, acquaintances $(47 \%)$ and family members $(28 \%)$. Neighbours' key influence on adoption was also noted by Opiyo [27], who found that both word-of-mouth 
endorsements and seeing installations were effective. Participants' recommendations did not always involve the same SHS provider, with $29 \%$ of recommenders owning a nonBboxx SHS. Potential explanations include the recommender being brand-agnostic, finding another company better than theirs or households being inspired to conduct their own research to choose a company that suits their needs post-recommendation.

\subsubsection{Brand Awareness}

The most common channels through which participants first heard about Bboxx were sales agents (48\%) and neighbours (46\%), whilst friends (11\%) and advertising (11\%) played a lesser role. The findings display the effectiveness of sales agents as a tool for raising awareness, revealing why many SHS companies utilise them. Although, Bugesera respondents were less likely than their Kayonza counterparts to first hear about Bboxx through sales agents (FET, $p$-value: 0.02). Previous studies also showcased neighbours' effectiveness in spreading awareness $[29,33]$. A social network study is required to examine whether peer effects exist in these settings and their impact on individuals' decision to purchase a SHS.

\subsection{Purchase}

\subsubsection{Purchasing Reasons}

The participants ranked their three main reasons for purchasing a SHS, which were weighted, where the second and third most important were multiplied by 0.66 and 0.33 , respectively, to reduce weightage compared to the top priority. This resulted in "clean energy source" as the top reason (39\%), followed by "improved and reliable lighting" $(33 \%)$ and "phone charging at home" (31\%) (Figure 4). The importance of lighting and phone charging is in line with prior research on SHSs adoption decisions [14,33,72]. A FG participant added a psycho-social dimension to this, saying: "do you know how shameful it is to go somewhere and find that they have light, whilst you are still living in darkness in your place?". The fourth priority was health, where households compared SHS benefits to current often polluting sources. This was validated in the FGs, where participants highlighted health issues they faced when using kerosene lamps. This demonstrates the need for comprehensive advertising, including associated health and lifestyle benefits to increase SHS understanding and adoption.

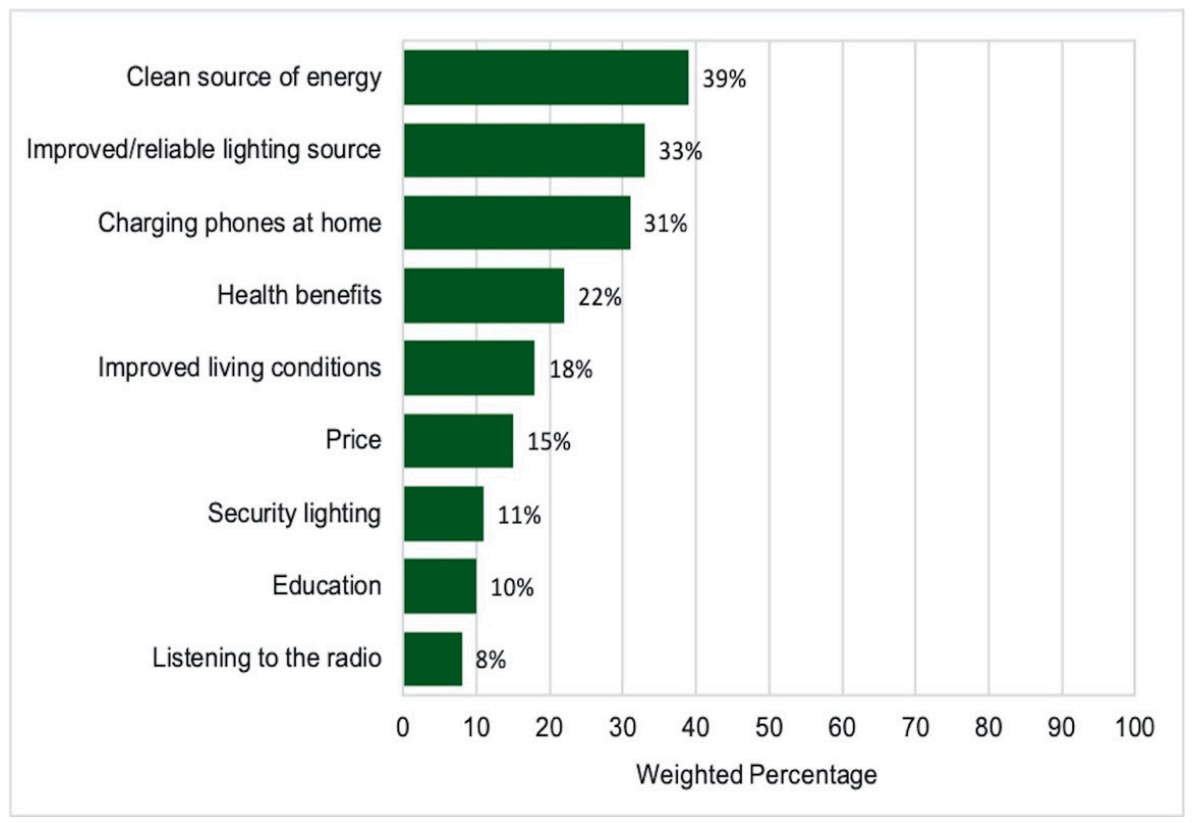

Figure 4. Weighted percentage of customer's most important sign-up reasons. 


\subsubsection{Purchase Location}

Customers purchase their SHS at a Bboxx shop, through a sales agent or a call centre. In this study, no participants used a call centre. Sales agent purchases were most common $(57 \%)$, whilst the remainder were at a shop. Most respondents that bought theirs in the shop $(60 \%)$ had been customers for less than a year. Conversely, long-term customers were more likely to sign up via sales agents (FET, $p$-value: 0.001 ). This is despite the company's number of shops and sales agents both increasing in past years. Given the volume and spread of SHSs, awareness and accompanying demand for them has risen, thus households are actively approaching SHS companies instead of waiting for sales agents. This is demonstrated by $70 \%$ of respondents who received a SHS recommendation from a SHS user purchasing theirs in a Bboxx shop rather than through a sales agent (FET, $p$-value: $1 \times 10^{-6}$ ). Gebreslassie [73] has also observed a burst of new customers, highlighting an increase in awareness and SHS availability. Multiple FG participants visited the provider's shop to examine the products offered before purchasing their SHS. However, households may receive this information from sales agents first and only make a purchase at the shop to see the SHS before committing.

Differences in districts were observed, where $63 \%$ of customers who purchased their SHS from a sales agent were Kayonza residents, despite Bugesera having more sales agents at the time, although this difference was not significant. Moreover, most lower income households ( $72 \%$ ) signed up via sales agents, compared to $42 \%$ of higher income households (FET, $p$-value: 0.004). This may highlight the rural-urban divide, with shops usually situated in town centres.

\subsubsection{Purchase Barriers}

Participants believed that the main reasons preventing others in their neighbourhood from purchasing a SHS were price $(69 \%)$, believing that signing up required too much effort $(41 \%)$ and being unaware of SHSs $(25 \%)$. Too much effort may encompass the time spent travelling to the shop, the sign-up process or the actual installation. Cost was perceived to be a bigger issue for participants in Bugesera (58\%), whilst most Kayonza residents (61\%) believed signing up to a SHS required too much effort. Kayonza's larger area size potentially contributed to that reason's prominence. Finally, $80 \%$ of the customers believing their neighbours to be unaware of SHSs were higher income households (FET, $p$-value: 0.0001). Future research should investigate barriers for sign-up, as well as the perceived and actual SHS awareness levels split by socio-demographic factors such as gender.

\subsection{Usage}

\subsubsection{Activities}

Participants' $(n=97)$ four main SHS uses were phone charging $(97 \%)$, lighting for security $(88 \%)$, socialising $(82 \%)$ and completing household chores (80\%) (Figure 5). SHS usage can lead to an increase in perceived security, where customers install bulbs outside their homes to reduce tripping risks and deter thieves [14,74]. The almost universal usage of SHSs for security highlights how much households value this option, despite not featuring amongst the key purchase reasons. Companies should account for this usage in their system designs, because continued night-time consumption has been classed as non-optimal utilisation [75]. Activities performed were split by income, with lower income households more likely to use their SHS to complete household chores (FET, $p$-value: 0.05 ) and less likely to use it for leisure purposes (FET, $p$-value: 0.0005 ) than higher income respondents. Most higher income (67\%) respondents used it for light provision whilst cooking (FET, $p$-value: 0.05$)$. Finally, participants over 39 years of age were less likely to use their SHS for leisure than their younger counterparts (FET, $p$-value: 0.02). This study also found that $57 \%$ of participants $(n=79)$ observed their children's studying time increase after SHS adoption, corroborating previous research [19,37]. Respondents attributed this to extended study hours due to the presence of light in the house and the ability to study at night. Participants that stated having more than five household occupants were more likely 
to report that children increased their studying time after SHS adoption (FET, $p$-value: $0.005)$. This showcases that the number and type of occupants can impact the value gained through electrification efforts, as previously highlighted [15].

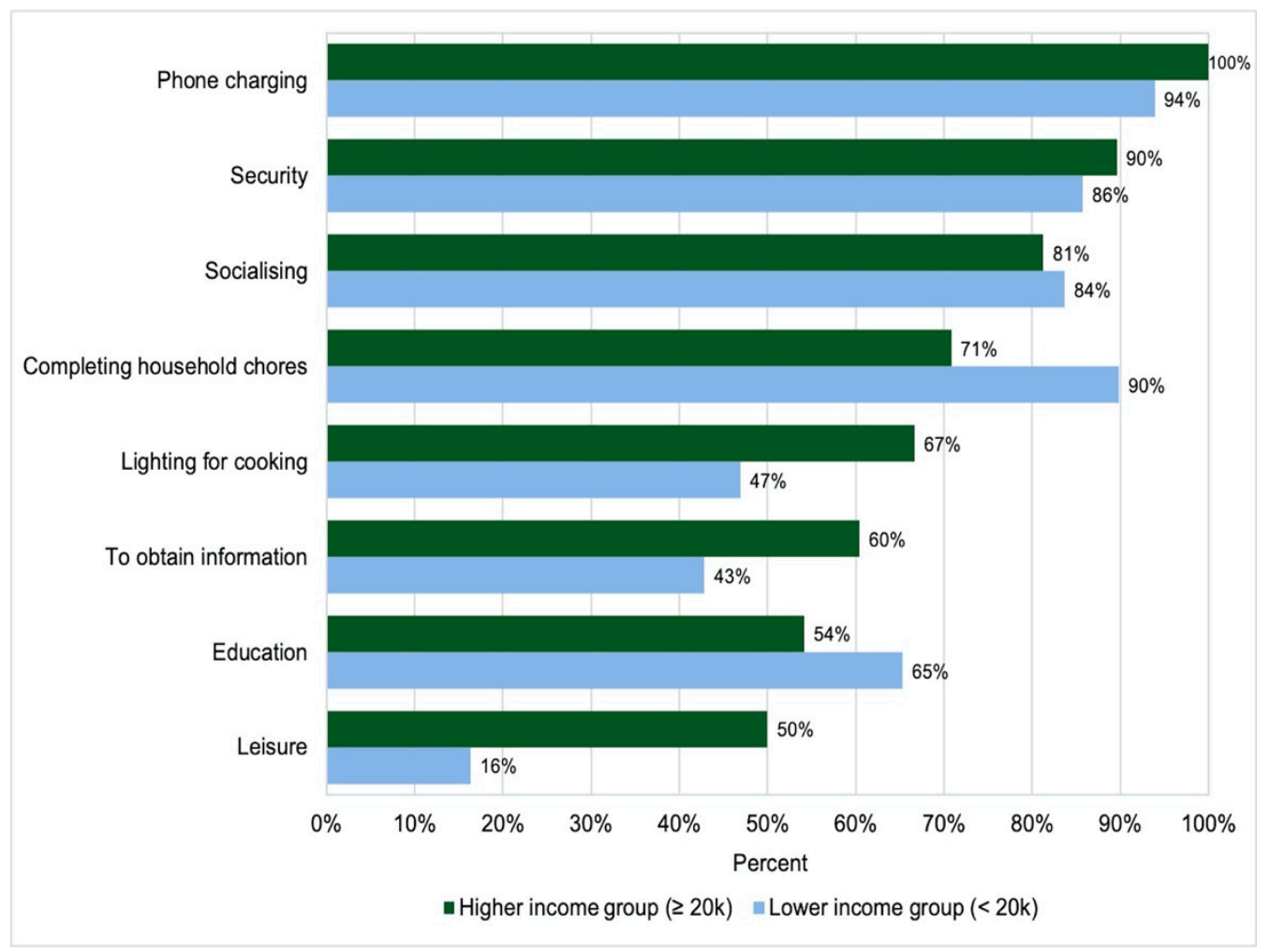

Figure 5. SHS activities split by income.

Only $10 \%$ of households used their SHS for income generation. There was a difference between new and seasoned customers, with $90 \%$ of these income generators being customers for less than a year (FET, $p$-value: 0.001). All ten households offered phone charging services, whilst two participants additionally provided television access and shaving services, respectively. Few customers using SHS for income generation is in line with previous research $[14,32]$. The reasons for this should be evaluated further to support productive energy uses in households.

\subsubsection{Average Appliance Usage}

Respondents $(n=64)$ were questioned on their average appliance usage in the morning, afternoon, evening and night. Figure 6 highlights that almost all bulb and television owners utilised these appliances in the evening. Being self-reported data, it may be inaccurate, but it still provides an insight into households' appliance usage.

\subsubsection{Energy Usage Change}

Participants were asked if they believed their energy consumption changed after the first month of SHS usage. Most (52\%) thought it stayed the same, 22\% were not sure, $21 \%$ observed a decrease and only $5 \%$ reported an increase in their energy usage. They attributed this increase to more sunshine, whilst the energy usage decrease was predominately blamed on battery issues. Although, it is challenging to realise one's own energy consumption changes and the accuracy of these statements need to be verified with usage data. 


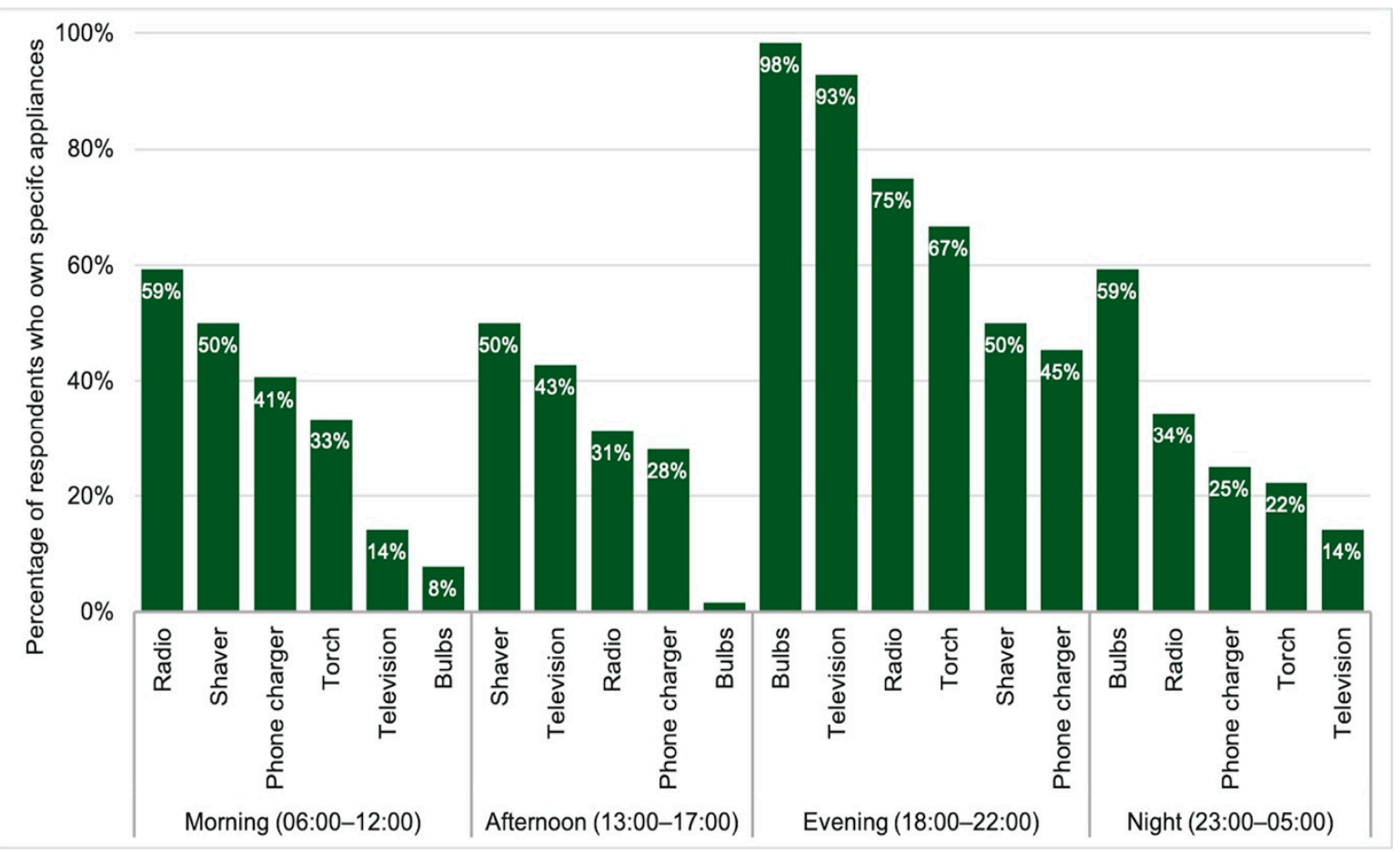

Figure 6. Average appliance usage throughout the day as a percentage of appliance owners.

Special occasions, such as public holidays, can change households' energy usage [76]. In this study, only $19 \%$ of participants reported increased usage due to special occasions. Seasonality effects were also investigated, where only $25 \%$ of customers' energy usage changed in particular months. This suggests that consumption remains relatively stable with respect to special occasions and months. However, half of all participants struggled to pay for their SHS in specific months, where April, October and November were most challenging. The principal causes were lower agricultural productivity, unstable financial capacity and agricultural investments, such as buying seeds. This suggests that SHSs are reaching low-income households and more support is needed to maintain affordability across the year.

\subsection{Recommend SHS}

The likelihood of recommending a Bboxx SHS to other people on a scale of zero (would not recommend) to ten (definitely would recommend) was ascertained, with the average being 7.7. Higher income households were less likely to recommend the SHS compared to lower income respondents (MWW, $p$-value: 0.04). Out of the respondents providing a high likelihood to recommend score (9-10), most wanted to upgrade in the future $(88 \%)$, thereby strengthening their commitment to the company and their continued SHS use. In contrast, $80 \%$ of participants not wanting to upgrade reported lower likelihood to recommend scores (0-8) (FET, $p$-value: 0.02 ). Overall, $65 \%$ of customers talked to someone about their SHS after purchasing it, with most respondents $(56 \%)$ reporting that the person they talked to consequently signed up for a SHS. The number of people converted to SHS customers ranged from 1 to 15 (Figure 7). On average, customers converted two people, which extrapolated to the larger population means that word-ofmouth endorsements could double a company's customer base. 


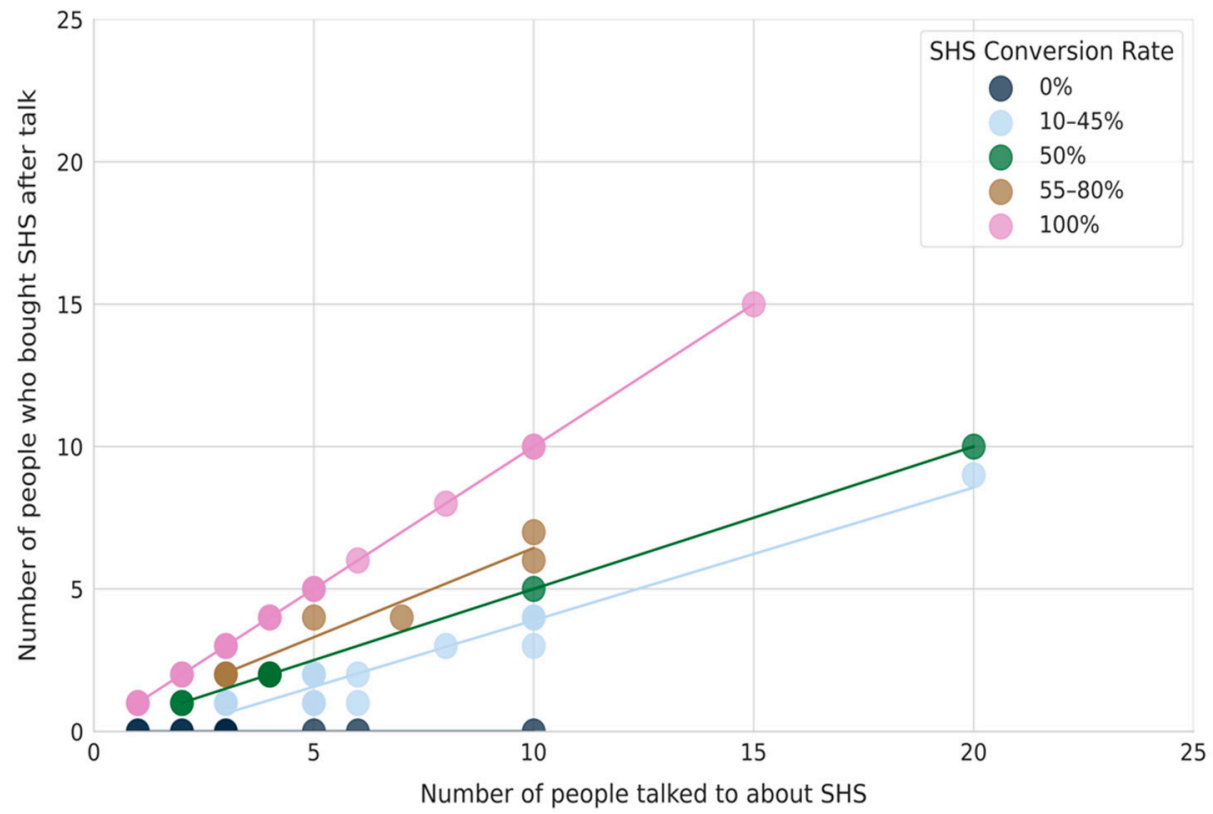

Figure 7. Number of people talked to about SHS versus number buying a SHS afterwards.

A $100 \%$ conversion was achieved by $35 \%$ of customers, where everyone they discussed the SHS with bought one afterwards (Figure 8). No referral scheme was in place, therefore some FG participants mentioned wanting recognition for these efforts through rewards, such as free days of usage. Future research could examine different referral schemes' impact on SHS adoption, although the literature shows that their effects may not always be positive depending on the product and rewards [77].

30

25

23

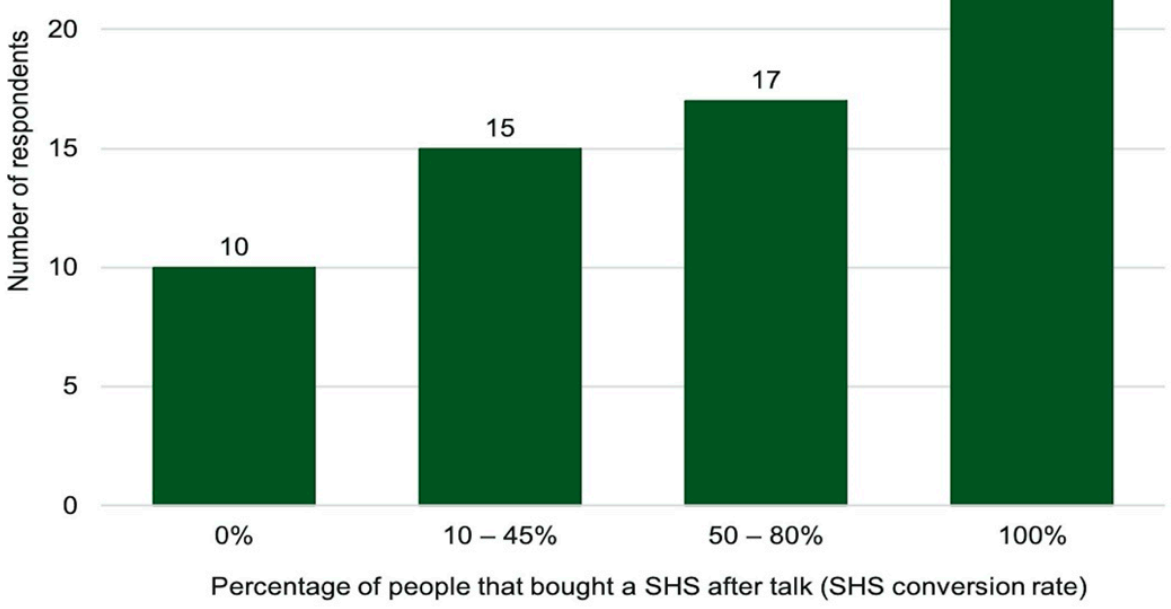

Figure 8. Number of respondents per SHS conversion rate.

4.6. Upgrade

4.6.1. Upgrading Decision

Only $14 \%$ of households upgraded to other Bboxx appliances, out of which $43 \%$ chose a television. Lower income households were less likely to have upgraded than their higher income counterparts (FET, $p$-value: 0.003). Prior studies found mixed evidence of 
upgrades, with Opiyo [48] observing a high level of upgrades compared to findings by Bisaga and Parikh [49]. The majority of participants (76\%) wanted to upgrade to other appliances in the future. The main reasons for wanting to upgrade are related to the chosen appliances and comprised watching news on the television, lighting more rooms and hair shaving. Many highlighted the importance of watching television with their household members, particularly their children, who would otherwise watch it somewhere else in the neighbourhood. Most respondents $(74 \%)$ whose energy needs were met by using a SHS would still like future upgrades, highlighting that their aspirations were not yet fulfilled.

Among those who never upgraded but want to in the future, $85 \%$ said they could not afford it, whilst $15 \%$ did not believe the price was worth the appliance. To investigate this, the telephone interviewees were asked if they knew the desired appliance's cost, with $65 \%$ of respondents $(n=34)$ being unaware. However, this is a small sample and further examination is needed to understand the effect of mis-or lack of information and cost perceptions on user behaviour. Respondents under the age of 40 were more likely than their older counterparts to not have upgraded yet due to a belief that the price was not worth the appliance (FET, $p$-value: 0.03 ). Unwillingness to upgrade mainly stemmed from satisfaction with current appliances and not needing new ones. Customers desiring only basic appliances should be identified early by companies because their needs could be met by smaller capacity SHSs. This is pertinent in the backdrop of the SHS industry's push towards larger capacity SHSs with more accompanying appliances, including for income generation, as some customers underutilise these and are thus overcharged.

\subsubsection{Appliances}

The top four appliances customers wanted to purchase were televisions (71\%), bulbs $(37 \%)$, shavers $(21 \%)$ and radios $(16 \%)$. This strong desire for televisions is in line with previous studies $[14,33]$. Most respondents wanting a shaver $(69 \%)$ were less than 40 years old. A FG participant highlighted that upgrading to a shaver was important for hygiene reasons and to avoid issues such as dandruff and long barber queues.

Households were questioned on desired appliances currently not offered by Bboxx, where irons $(66 \%)$, smart phones $(45 \%)$ and fridges (34\%) were most popular. Of the people selecting irons, $59 \%$ were men. The FGs indicated that the type of trousers men preferred wearing required ironing and the lack of suitable irons pushes them to choose less preferred garments. This highlights shifting aspirations, beyond meeting basic energy needs [14]. Aspirations were linked to income, as $65 \%$ of participants wanting a fridge and $75 \%$ of people coveting a laptop were higher income households (FET, $p$-value: $0.02, p$-value: 0.03 respectively).

\subsection{Retain SHS}

\subsubsection{Energy Amount Satisfaction}

The energy amount each household receives varies depending on factors such as location and battery age. Most customers (86\%) reported the SHS meeting their energy needs. The remainder (14\%) were concerned that the SHS could not support additional appliances. Unsatisfied respondents (14\%) were highly likely to talk to others about their SHS after purchase, with $93 \%$ having done so, compared to their satisfied counterparts (FET, $p$-value: 0.02 ). This highlights the role negative word-of-mouth reviews may play in the SHS market, although it might have a smaller impact on the receiver's opinion of the product than its positive counterpart [78]. Overall, only $6 \%$ of respondents were "dissatisfied" or "very dissatisfied" with the amount of time they could use their SHS after dark, with the majority ( $81 \%$ ) either "very satisfied" or "satisfied". However, the aim should be to realise households' energy aspirations and not only meet their needs. Particularly, as $39 \%$ of households experienced their battery running out whilst using the SHS, including respondents whose energy needs were met. To investigate how closely satisfaction levels are related to SHS retention rates, future longitudinal studies should record customers' satisfaction levels throughout their entire PAYG SHS customer journey. 


\subsubsection{Future Primary Energy Source}

Future energy aspirations closely relate to customer retention. Participants rated their likelihood of a SHS being their primary energy source in the next five years on a scale of zero to ten $(0=$ SHS will not be their primary energy source, $10=$ definitely will be SHS), where the mean was 7.6. Higher income participants, especially male respondents, gave lower scores on average than their lower income counterparts (MWW, $p$-value: 0.01 ) (Figure 9), potentially signifying their greater ability to switch to more expensive energy sources in future.

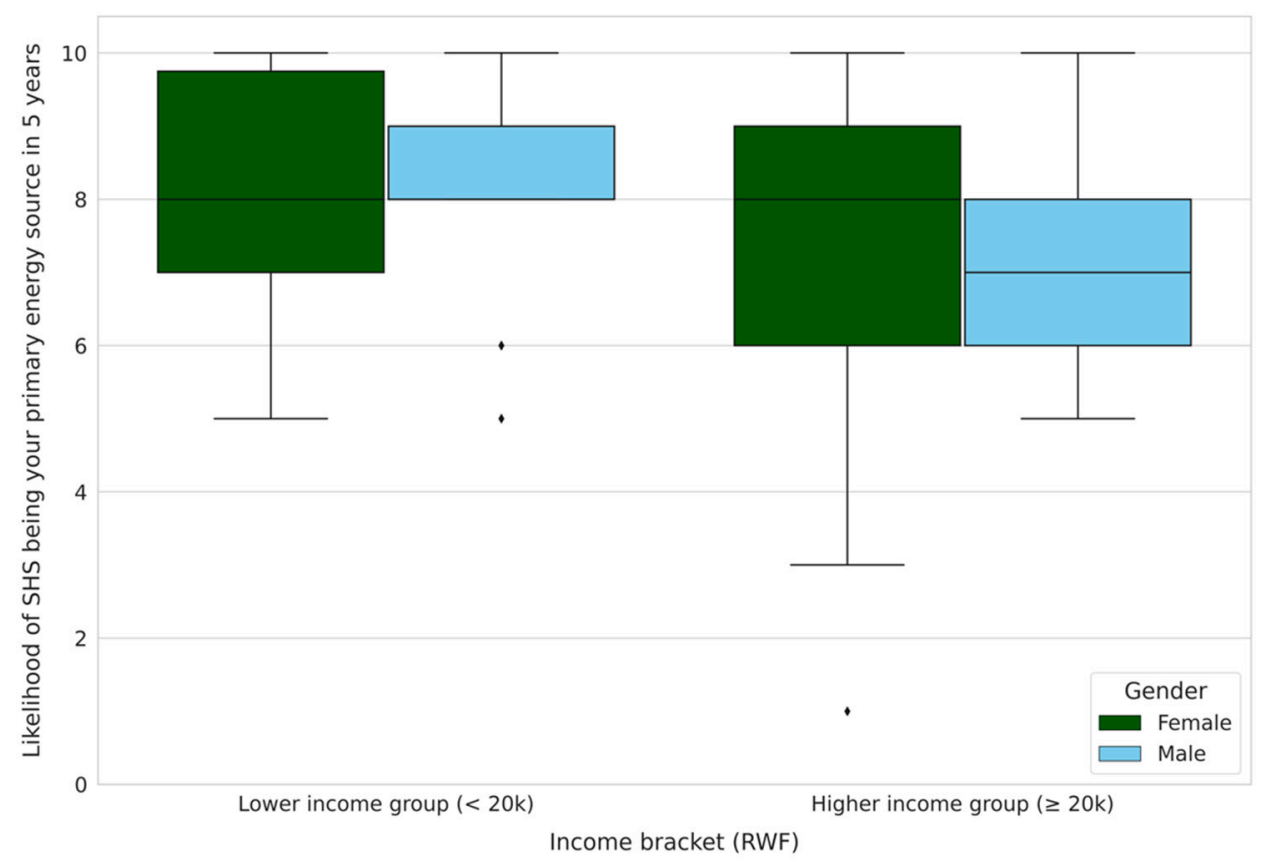

Figure 9. Likelihood of SHS as the primary energy source in 5 years' time, by income and gender.

Respondents that wanted a future grid connection were less likely $($ mean $=7.3$ ) to believe that a SHS would remain their future primary energy source in five years' time compared to their counterparts (mean $=8.4)(\mathrm{MWW}, p$-value: 0.001). However, the relatively high mean score for participants desiring grid access may reveal that many are only planning on switching after five years have passed. Respondents might also change SHS companies in those five years. This study discovered this is not uncommon, with $20 \%$ of respondents having a previous SHS provider. Seasoned Bboxx customers were less likely to have owned a previous SHS compared to their newer counterparts (FET, $p$-value: 0.05). A FG participant had signed up to two previous SHS companies, abandoning both due to poor service until acting on a Bboxx recommendation. This raises questions around SHSs' sustainability when households experience maintenance issues, particularly if appropriate after-sales services are lacking. More research is thus needed, examining the underpinning reasons and wider consequences of switching. Companies could be inspired to adopt better after-sales strategies to persuade households to remain customers if this trend persists. Moreover, as the market expands, upholding consumer rights becomes increasingly important, ensuring no disproportionate penalisation for switching SHS companies.

\subsection{Switching Energy Source \\ 4.8.1. Energy Stacking}

Households may switch from their previous energy sources at any point after purchasing the SHS (Figure 1). Participants' prior energy sources included candles $(42 \%)$, paraffin lamps $(39 \%)$, torches $(22 \%)$, grid electricity $(16 \%)$ and their mobile phone torch $(16 \%)$. Multiple studies found energy stacking to be common, thus indicating that households 
do not entirely switch to SHSs $[49,79,80]$. However, of the interviewed participants, only $6 \%$ of customers used candles for lighting and $4 \%$ used grid electricity in addition to their SHS. During times where their SHS is not in use, however, customers likely resort to other energy sources [14]. The PAYG SHS customer journey is thus particularly dependent on the household's financial situation.

\subsubsection{Electricity Grid}

Most households (69\%) desired a grid connection in the future. Respondents that had started an education were more likely to desire a grid connection, with all university attendees $(n=5)$ wanting to switch (FET, $p$-value: $0.003, p$-value: 0.003 , respectively). The likelihood of a households' grid connection was dependent on the distance from the nearest grid connection point, where only $24 \%$ lived less than 10 minutes away. Lower income households and respondents that have been Bboxx customers for over a year were more likely to live further than 10 minutes away from the electricity grid compared to their counterparts (FET, $p$-value: $0.008, p$-value: 0.0009 , respectively).

Most participants (58\%) living less than 10 minutes away wanted to switch to the grid. Households not wanting a future connection that resided closer to the grid $(n=10)$ felt that the grid might pose risks, such as fire, whilst ones further away $(n=21)$ were satisfied with their SHS. A FG participant believed that SHSs are safer for children, stating that "a kid can touch a socket and the whole house catches fire" regarding the national grid. The perceived risks are among the key influencing factors in a household's switching decision and thus need to be further investigated. A large proportion of newer customers (41\%) lived less than 10 minutes away from the electricity grid, potentially highlighting SHSs' growing encroachment into electricity grid areas.

\section{Conclusions}

This paper presents the first PAYG SHS customer journey framework, examining the pre-to post-adoption of SHS users. It consists of seven stages that a household may experience: awareness and understanding, purchase, usage, upgrade, recommendation, switching energy source and SHS retention. The steps taken by each PAYG SHS customer vary, but examining them can foster a deeper understanding of the different customer profiles and identify where more research is required. It also highlights the non-linear and cyclical nature of the journey, acknowledging that a household operates within social networks in which they could inspire or be influenced by others. Moreover, external political, economic, social and technological factors may impact the adoption decision. This paper utilised this framework to examine a case study in Rwanda, investigating PAYG SHS customers' experiences throughout their journey to add to the growing literature around this topic.

The case study revealed new insights into consumer behaviour within each framework step. The paper has highlighted the growing importance of SHS recommendations in raising awareness of SHSs over the last four years. This contributes to the findings that SHS awareness no longer appears to be a major adoption barrier, because participants waited on average over a year after becoming aware before purchasing a SHS. Another novel finding was that households' main purchase reasons were not activity-based, instead consisting of using a clean energy source, illustrating the value placed on health and the environment. Companies should thus place greater emphasis on health benefits when marketing SHSs. Despite the majority of consumers stating that their energy needs were met by SHSs, most wanted to upgrade to new appliances in the future, particularly televisions, highlighting shifting aspirations beyond meeting basic needs. This is accentuated by most participants desiring a future grid connection, although perceptions of grid-related risks were common and were found to be a deterrent for some participants. The frequency of grid-caused fires and electrocutions and the impact on people's attitudes should thus be examined.

This article also contributes to the evidence base of previous research discussed in the literature review. It shows the effectiveness of word-of-mouth endorsements in raising 
awareness, where almost half of respondents in this study received a recommendation from SHS users before purchasing theirs. Most participants in turn converted other households to SHS users. However, this study found that respondents with unmet energy needs were more likely to talk to others about their SHS than their satisfied counterparts, highlighting the potential of negative word-of-mouth effects. Future research should include peer effect studies evaluating the influence of social networks and information flow on SHS recommendations and adoption. In line with existing research, this study highlighted that the key SHS uses were phone charging, security and socialising. As outlined in previous studies, few respondents used their SHS for income generation, although $90 \%$ of them had only been customers for under a year. This signals a potential expansion of this usage amongst future customers, for which companies could prepare by widening the choice of compatible appliances on offer, for instance. Contrary to previous literature, participants engaged in limited energy stacking.

Future studies should utilise this framework to examine PAYG SHS customers in other countries and preferably with a larger sample size to build on this preliminary study. This would enable the testing of these findings and the development of a contextualised and localised evidence base for PAYG SHS customer journeys that captures and compares country-level differences within each step of the customer journey.

Author Contributions: Conceptualisation, V.K. and P.P.; data curation, V.K.; formal analysis, V.K.; funding acquisition, P.P.; investigation, V.K.; methodology, V.K., P.P. and I.B.; project administration, V.K.; supervision, P.P.; validation, V.K., P.P. and I.B.; visualization, V.K.; writing—original draft, V.K.; writing-review and editing, V.K., P.P. and I.B. All authors have read and agreed to the published version of the manuscript.

Funding: This research was funded by the Engineering and Physical Sciences Research Council, grant number [EP/N509577/1] and Royal Academy of Engineering, grant number [RCSRF1819 $\backslash 8 \backslash 38$ ]. The lead author also gratefully acknowledges UCL and Bboxx for funding her doctoral research.

Institutional Review Board Statement: The study was conducted according to the guidelines of the Declaration of Helsinki and approved by the Ethics Committee of University College London (UCL) (13937/001, 02.10.2018).

Informed Consent Statement: Informed consent was obtained from all subjects involved in the study.

Data Availability Statement: The data presented in this study are available on request from the corresponding author. The data are not publicly available due to privacy reasons.

Conflicts of Interest: The authors declare no conflict of interest. The funders had no role in the design of the study; in the collection, analyses or interpretation of data; in the writing of the manuscript or in the decision to publish the results.

Appendix A

Table A1. Extract of structured interview questions.

\begin{tabular}{|c|c|c|}
\hline Extract of Structured Interview Questions & Responses & Question Type \\
\hline $\begin{array}{l}\text { What is your gender? } \\
\text { What is your age? }\end{array}$ & Female; Male & $\begin{array}{l}\text { Binary multiple choice } \\
\text { Open-ended }\end{array}$ \\
\hline $\begin{array}{l}\text { How many people have consistently lived in your house } \\
\text { in the last } 12 \text { months (including yourself)? }\end{array}$ & & Open-ended \\
\hline What is your level of education? & $\begin{array}{c}\text { No education; I attended primary education } \\
\text { but did not complete it; I completed primary } \\
\text { education; I attended secondary education } \\
\text { but did not complete it; I completed } \\
\text { secondary education; I attended university } \\
\text { but did not graduate; I completed a } \\
\text { university degree }\end{array}$ & Binary multiple choice \\
\hline
\end{tabular}


Table A1. Cont.

\section{Extract of Structured Interview Questions}

How many separate rooms do you have in your property (including kitchen, bathroom, etc.)

What is your main source of income/occupation?

What was the average monthly income of your household in the last month?

Is the total income of your household approximately the same every month?

Why is your total income not the same every month?

When did you hear about solar home systems as a technology for the first time?

Did you possess a solar home system before purchasing a Bboxx system?

From what company did you purchase your previous solar home system?

How long have you been a Bboxx customer?

What were your top three reasons for signing up for Bboxx? (1st Choice)

What were your top three reasons for signing up for Bboxx? (2nd Choice)

What were your top three reasons for signing up for Bboxx? (3rd Choice)

Where did you purchase your Bboxx solar home system?

How did you first hear about Bboxx (select all that apply)?

Did someone who owns a solar home system recommend that you should purchase one?

Responses

$1 ; 2 ; 3 ; 4 ; 5 ; 6 ; 7 ; 8 ; 9 ; 10 ; 10+$

Less than RWF 2000; RWF 2001-3000; RWF 3001-4000; RWF 4001-5000; RWF

5001-10,000; RWF 10,001-15,000; RWF

15,001-20,000; RWF 20,001-30,000; RWF

30,001-40,000; RWF 40,001-50,000; RWF

50,001-100,000; RWF 100,001-150,000; RWF

150,001-200,000; RWF 200,001-250,000; RWF

250,001-300,000; RWF 300,001-350,000; More than RWF 350,000; Does not want to answer

$$
\text { Yes; No }
$$

Less than 6 months ago; 6 months ago; 1 year ago; 2 years ago; 3 years ago; 4 years ago;

5 years ago; More than 5 years ago

$$
\text { Yes; No }
$$

Mobisol; D-light; Ignite; Zola; Locally made system; Other

Price; Improved/reliable lighting source; Charging phones at home; Clean source of energy; Health benefits; Education (e.g.,

children studying); Improved living conditions; After-sales services from Bboxx; Social status; Security lighting; Listening to the radio; Watching television; Long-term relationship with BBOXX through Energy Service Fee; Other

Price; Improved/reliable lighting source; Charging phones at home; Clean source of energy; Health benefits; Education (e.g.,

children studying); Improved living conditions; After-sales services from Bboxx; Social status; Security lighting; Listening to the radio; Watching television; Long-term relationship with BBOXX through Energy Service Fee; Other

Price; Improved/reliable lighting source; Charging phones at home; Clean source of energy; Health benefits; Education (e.g.,

children studying); Improved living conditions; After-sales services from Bboxx; Social status; Security lighting; Listening to the radio; Watching television; Long-term relationship with BBOXX through Energy Service Fee; Other

Bboxx store; From Bboxx sales agent; At a marketing event; Other

Family; Friend; Neighbour; Marketing event; Internet; Advertising (e.g., TV, radio, newspaper, billboards); BBOXX Sales agents; In the BBOXX shop; Other

$$
\text { Yes; No }
$$

Question Type

Binary multiple choice

Open-ended

Binary multiple choice

Binary multiple choice

Open-ended

Binary multiple choice

Binary multiple choice

Binary multiple choice

Open-ended

Binary multiple choice

Binary multiple choice

Binary multiple choice

Binary multiple choice

$$
\begin{gathered}
\text { Multiple answer } \\
\text { multiple choice }
\end{gathered}
$$

Binary multiple choice 
Table A1. Cont.

\section{Extract of Structured Interview Questions}

How do you know this person (select all that apply)?

From what company did that person purchase their solar home system?

Since becoming a Bboxx customer and installing the system with the initial set of appliances, have you added on any other appliances (i.e., have you upgraded your system)?

Which appliances did you upgrade to (select all that apply)?

Would you consider upgrading to other appliances in the future?

Why do you not want to upgrade to other appliances in the future?

Which appliances would you like to purchase in the future (select all that apply)?

When do you think you will upgrade?

Why would you like to upgrade?

What has prevented you from upgrading so far (select all that apply)?

What appliances, that Bboxx are currently NOT offering, would you like to have (select all that apply)?

Do you still utilise other energy sources, on top of the Bboxx system (e.g., candles, kerosene, batteries)?

Which other lighting/power sources are you currently using (select all that apply)?

What were your previous light sources BEFORE you signed up to Bboxx (select all that apply)?

What were your previous power sources BEFORE you signed up to Bboxx (select all that apply)?

On average, how many hours of the day do you have your bulbs switched on?

On average, what time of day are your bulbs switched on (select all that apply)?

On average, how many hours of the day do you charge your phone with the Bboxx phone charger?

On average, what time of day do you charge your phone with the Bboxx phone charger (select all that apply)?

On average, how many hours of the day do you have your Bboxx radio switched on?

On average, what time of day is your Bboxx radio switched on (select all that apply)?
Responses

Question Type

Close family (your parents, siblings or children); Extended family (e.g.,

uncles/aunts, grandparents); Friend; Acquaintance; Work colleague; Neighbour; Other

Bboxx; Mobisol; D-light; Ignite; Zola; Locally made system; Other

Yes; No

Phone Charger; Bulbs; Tube light (Torch); Radio; Television; Shaver; Other

$$
\text { Yes; No }
$$

Phone Charger; Bulbs; Tube light (Torch); Radio; Television; Shaver; Other In the next month; In the next 6 months; In the next year; More than a year; Do not know/not sure

I cannot afford it; I do not believe that the price is worth the appliance; Not decided what appliance to purchase first; Not had time to upgrade; Other

Iron; Kettle; Fridge; Mobile Phone; Laptop; Other Yes; No

Mobile phone light; Kerosene/Paraffin lamp; Candles; Torch; Batteries; Grid Electricity; Other

Mobile phone light; Candles;

Kerosene/Paraffin lamp; Bulbs or tube fixed to ceiling or wall; Battery powered moveable light; Solar lantern; Rechargeable Battery; Grid Electricity; Other

Dry-cell battery; Rechargeable big battery; Generator; Solar home system; Grid Electricity; No previous power source; Other

Morning (06:00-12:00); Afternoon (13:00-17:00); Evening (18:00-22:00); Night (23:00-05:00)

Morning (06:00-12:00); Afternoon (13:00-17:00); Evening (18:00-22:00); Night (23:00-05:00)

Morning (06:00-12:00); Afternoon (13:00-17:00); Evening (18:00-22:00); Night (23:00-05:00)
Multiple answer multiple choice

Binary multiple choice

Binary multiple choice

Multiple answer

Binary multiple choice

Open-ended

Multiple answer multiple choice

Binary multiple choice

Open-ended

Multiple answer multiple choice

Multiple answer multiple choice

Binary multiple choice

Multiple answer multiple choice

Multiple answer multiple choice

Multiple answer multiple choice

Open-ended

Multiple answer multiple choice

Open-ended

Multiple answer multiple choice

Open-ended

Multiple answer multiple choice multiple choice 
Table A1. Cont.

\section{Extract of Structured Interview Questions \\ On average, how many hours of the day do you have your television switched on?}

On average, what time of day is your television switched on (select all that apply)?

On average, how many hours of the day do you use your shaver?

On average, what time of day do you use your shaver (select all that apply)?

What activities do you use the system for (select all that apply)?

Are your children spending more time studying, since you purchased your solar home system?

Why are your children spending more time studying, since you purchased your solar home system?

Overall, do you believe that the amount of energy you use has changed from the first month you got your Bboxx system to now?

Why has your energy usage increased?

Why has your energy usage decreased?

Does your energy usage increase on special occasions (e.g., holidays, festivals, sport events)?

Are there specific months in which you use more or less energy than normal?

In which months do you use the system more than average (select all that apply)?

Why do you the system more than average in those months?

In which months do you use the system less than average (select all that apply)?

Why do you the system less than average in those months?

Are there specific months you struggle to pay for your system?

In which specific months do you struggle to pay for your system (select all that apply)?

Why do you struggle to pay for the system in these months?

Are you using your system as an additional income source (e.g., by offering a phone charging service powered by your solar system)?

What system-based services are you offering to earn additional income (select all that apply)?

Does the Bboxx system meet your energy needs?

Why does the Bboxx system not meet your energy needs?

How satisfied or dissatisfied are you with the amount of time you can use the system/appliances for during the night?

Has the battery of your solar system ever run out whilst you were using the system?

On a scale of $0-10$, how likely is it that a solar system

will be your primary energy source in the next 5 years $(0$ = definitely not, 10 = definitely will be)?

Responses

Question Type

Open-ended

Morning (06:00-12:00); Afternoon

(13:00-17:00); Evening (18:00-22:00);

Night (23:00-05:00)

Morning (06:00-12:00); Afternoon

(13:00-17:00); Evening (18:00-22:00);

Night (23:00-05:00)

Yes; No

Yes, it has increased; Yes, it has decreased; No, it has stayed the same; Not sure/I do not know

Yes; No

Yes; No

January; February; March; April; May; June; July; August; September; October; November; December

January; February; March; April; May; June; July; August; September; October; November; December

\section{Yes; No}

January; February; March; April; May; June; July; August; September; October; November; December

Yes; No

Phone charging; Lighting provision; TV access; Shaving service; Other Yes; No

Very satisfied; Satisfied; Neither satisfied nor dissatisfied; Dissatisfied; Very dissatisfied; I do not know

$$
\text { Yes; No }
$$

$0 ; 1 ; 2 ; 3 ; 4 ; 5 ; 6 ; 7 ; 8 ; 9 ; 10$ Binary multiple choice

Multiple answer multiple choice

Open-ended

Multiple answer multiple choice

Multiple answer multiple choice

Binary multiple choice

Open-ended

Binary multiple choice

Open-ended

Open-ended

Binary multiple choice

Binary multiple choice

Multiple answer multiple choice

Open-ended

Multiple answer multiple choice

Open-ended

Binary multiple choice

Multiple answer multiple choice

Open-ended

Binary multiple choice

Multiple answer multiple choice Binary multiple choice

Open-ended

Likert scale

Rating scale 
Table A1. Cont.

\begin{tabular}{|c|c|c|}
\hline Extract of Structured Interview Questions & Responses & Question Type \\
\hline How long does it take you to walk to the electricity grid? & $\begin{array}{l}0 \text { min; } 1-5 \mathrm{~min} ; 6-10 \mathrm{~min} ; 11-15 \mathrm{~min} ; 16-20 \\
\min \text {; } 21-25 \mathrm{~min} ; 26-30 \mathrm{~min} \text {; More than } 30 \mathrm{~min}\end{array}$ & Binary multiple choice \\
\hline $\begin{array}{l}\text { Would you like to be connected to the electricity grid in } \\
\text { the future? }\end{array}$ & Yes; No & Binary multiple choice \\
\hline $\begin{array}{c}\text { Why would you not like to be connected to the } \\
\text { electricity grid? }\end{array}$ & & Open-ended \\
\hline $\begin{array}{l}\text { Have you ever talked to anyone about your solar home } \\
\text { system after signing up for it? }\end{array}$ & Yes; No & Binary multiple choice \\
\hline $\begin{array}{c}\text { How many people did you talk to about your solar } \\
\text { home system after signing up for it? }\end{array}$ & & Open-ended \\
\hline $\begin{array}{l}\text { Did any of the people you talked to about your solar } \\
\text { home system sign up for one after you spoke to them } \\
\text { about it? }\end{array}$ & Yes; No & Binary multiple choice \\
\hline $\begin{array}{l}\text { How many of the people you talked to about your solar } \\
\text { home system, signed up for one afterwards? }\end{array}$ & & Open-ended \\
\hline $\begin{array}{l}\text { What do you believe are the main reasons that prevent } \\
\text { people in your neighbourhood purchasing a solar home } \\
\text { system (select all that apply)? }\end{array}$ & $\begin{array}{l}\text { Cost; Unaware of solar home systems; } \\
\text { Previous bad experience with solar products; } \\
\text { Belief that it requires too much effort; Energy } \\
\text { Service Fee; Not sure; Other }\end{array}$ & $\begin{array}{l}\text { Multiple answer } \\
\text { multiple choice }\end{array}$ \\
\hline $\begin{array}{l}\text { On a scale of } 0-10, \text { how likely are you to recommend a } \\
\text { Bboxx system to others }(0=\text { definitely would not } \\
\text { recommend, } 10=\text { definitely would recommend }) ?\end{array}$ & $0 ; 1 ; 2 ; 3 ; 4 ; 5 ; 6 ; 7 ; 8 ; 9 ; 10$ & Rating scale \\
\hline
\end{tabular}

\section{Appendix B}

Table A2. Extract of focus group questions.

\section{Extract of Focus Group Questions}

Could each of you tell me how and when you heard of Bboxx for the first time and how you purchased it? When you decided to purchase the system, what factors were important to you?

Who or what influenced your decision to purchase the system?

What additional Bboxx appliances would you like to upgrade to in the future and why? What appliance, that Bboxx is currently not offering, would you like to have?

\section{References}

1. United Nations SDGs. Available online: https://sdgs.un.org/ (accessed on 27 November 2020).

2. IEA World Energy Outlook. 2019. Available online: https://www.iea.org/reports/world-energy-outlook-2019 (accessed on 3 April 2020).

3. IEA. Africa Energy Outlook 2019; IEA: Paris, France, 2019.

4. Lighting Global; GOGLA; ESMAP. Off-Grid Solar Market Trends Report 2020; ESMAP: Washington, DC, USA, 2020.

5. Kowsari, R.; Zerriffi, H. Three dimensional energy profile: A conceptual framework for assessing household energy use. Energy Policy 2011, 39, 7505-7517. [CrossRef]

6. Følstad, A.; Kvale, K. Customer journeys: A systematic literature review. J. Serv. Theory Pract. 2018, 28, 196-227. [CrossRef]

7. Lemon, K.N.; Verhoef, P.C. Understanding Customer Experience Throughout the Customer Journey. J. Mark. 2016, 80, 69-96. [CrossRef]

8. Sinitskaya, E.; Gomez, K.J.; Bao, Q.; Yang, M.C.; MacDonald, E.F. Designing linked journey maps to understand the complexities of the residential solar energy market. Renew. Energy 2020, 145, 1910-1922. [CrossRef]

9. Ortbal, K.; Frazzette, N.; Mehta, K. Stakeholder journey mapping: An educational tool for social entrepreneurs. Procedia Eng. 2016, 159, 249-258. [CrossRef]

10. Ho, J.K.-K. Formulation of a Systemic PEST Analysis for Strategic Analysis. Eur. Acad. Res. 2014, 2, $6478-6492$.

11. Bimenyimana, S.; Asemota, G.N.O.; Li, L. The State of the Power Sector in Rwanda: A Progressive Sector with Ambitious Targets. Front. Energy Res. 2018, 6. [CrossRef]

12. Nieuwenhout, F.D.; van Dijk, A.; van Dijk, V.A.; Hirsch, D.; Lasschuit, P.; van Roekel, G.; Arriaza, H.; Hankins, M.; Sharma, B.D.; Wade, H. Monitoring and Evaluation of Solar Home Systems: Experiences with Applications of Solar PV for Households in Developing Countries; The Netherlands Energy Research Institute: Petten, The Netherlands, 2000. 
13. Adwek, G.; Boxiong, S.; Ndolo, P.O.; Siagi, Z.O.; Chepsaigutt, C.; Kemunto, C.M.; Arowo, M.; Shimmon, J.; Simiyu, P.; Yabo, A.C. The Solar Energy Access in Kenya: A Review Focusing on Pay-As-You-Go Solar Home System; Springer: Dordrecht, The Netherlands, 2019; ISBN 0123456789.

14. Bisaga, I. Scaling Up Off-Grid Solar Energy Access through Improved Understanding of Customers' Needs, Aspirations and Energy Use of Decentralised (Smart) Solar Home Systems-A Case Study of Bboxx Customers in Rwanda. Ph.D. Thesis, University College London, London, UK, 2018.

15. Smith, M.G.; Urpelainen, J. Early Adopters of Solar Panels in Developing Countries: Evidence from Tanzania. Rev. Policy Res. 2014, 31, 17-37. [CrossRef]

16. Rahut, D.B.; Behera, B.; Ali, A.; Marenya, P. A ladder within a ladder: Understanding the factors influencing a household's domestic use of electricity in four African countries. Energy Econ. 2017, 66, 167-181. [CrossRef]

17. Dugoua, E.; Urpelainen, J. Relative deprivation and energy poverty: When does unequal access to electricity cause dissatisfaction? Int. J. Energy Res. 2014, 38, 1727-1740. [CrossRef]

18. Jacobson, A. Connective Power: Solar Electrification and Social Change in Kenya. World Dev. 2007, 35, 144-162. [CrossRef]

19. Hakiri, J.; Moyo, A.; Prasad, G. Assessing the role of solar home systems in poverty alleviation: Case study of Rukungiri district in Western Uganda (November, 2015). In Proceedings of the 2016 International Conference on the Domestic Use of Energy, Cape Town, South Africa, 30-31 March 2016; pp. 1-9. [CrossRef]

20. Guta, D.D. Determinants of household adoption of solar energy technology in rural Ethiopia. J. Clean. Prod. 2018, 204, 193-204. [CrossRef]

21. Mutua, J.; Kimuyu, P. Exploring the Odds for Actual and Desired Adoption of Solar Energy in Kenya; Environment for Development Initiative: Gothenburg, Sweden, 2015.

22. Hirmer, S.; Guthrie, P. The benefits of energy appliances in the off-grid energy sector based on seven off-grid initiatives in rural Uganda. Renew. Sustain. Energy Rev. 2017, 79, 924-934. [CrossRef]

23. Katikiro, R.E. Prospects for the Uptake of Renewable Energy Technologies in Rural Tanzania. Energy Procedia 2016, 93, 229-233. [CrossRef]

24. Green, J.M.; Erskine, S.H. Solar (photovoltaic) systems, energy use and business activities in Maphephethe, KwaZulu-Natal. Dev. South. Afr. 1999, 16, 221-237. [CrossRef]

25. Ondraczek, J. The sun rises in the east (of Africa): A comparison of the development and status of solar energy markets in Kenya and Tanzania. Energy Policy 2013, 56, 407-417. [CrossRef]

26. Martinot, E.; Cabraal, A.; Mathur, S. World Bank/GEF solar home system projects: Experiences and lessons learned 199320001Eric Martinot conducted the work herein as an Associate of the Stockholm Environment Institute, Boston. He currently works for the Global Environment Facility. Anil Cabra. Renew. Sustain. Energy Rev. 2001, 5, 39-57. [CrossRef]

27. Opiyo, N. Impacts of neighbourhood influence on social acceptance of small solar home systems in rural western Kenya. Energy Res. Soc. Sci. 2019, 52, 91-98. [CrossRef]

28. Opiyo, N. A survey informed PV-based cost-effective electrification options for rural sub-Saharan Africa. Energy Policy 2016, 91, 1-11. [CrossRef]

29. BBOXX Research Brief (Issue 03): How Do Our Customers Learn about Us? The Trend Is Shifting. Available online: https: / / www.bboxx.co.uk/research-brief-issue-03/ (accessed on 2 June 2020).

30. Holtorf, H.; Urmee, T.; Calais, M.; Pryor, T. A model to evaluate the success of Solar Home Systems. Renew. Sustain. Energy Rev. 2015, 50, 245-255. [CrossRef]

31. Barrie, J.; Cruickshank, H.J. Shedding light on the last mile: A study on the diffusion of Pay As You Go Solar Home Systems in Central East Africa. Energy Policy 2017, 107, 425-436. [CrossRef]

32. Stojanovski, O.; Thurber, M.; Wolak, F. Rural energy access through solar home systems: Use patterns and opportunities for improvement. Energy Sustain. Dev. 2017, 37, 33-50. [CrossRef]

33. GOGLA; Altai Consulting. Powering Opportunity The Economic Impact of Off-Grid Solar; GOGLA: Utrecht, The Netherlands, 2018.

34. Kennedy, R.; Numminen, S.; Sutherland, J.; Urpelainen, J. Multilevel customer segmentation for off-grid solar in developing countries: Evidence from solar home systems in Rwanda and Kenya. Energy 2019, 186, 115728. [CrossRef]

35. Bisaga, I. Innovation for Off-Grid Solar Rural Electrification. In Affordable and Clean Energy; Springer: Berlin/Heidelberg, Germany, 2020; pp. 1-11. ISBN 9783319710570.

36. Zubi, G.; Dufo-López, R.; Pardo, N.; Pasaoglu, G. Concept development and techno-economic assessment for a solar home system using lithium-ion battery for developing regions to provide electricity for lighting and electronic devices. Energy Convers. Manag. 2016, 122, 439-448. [CrossRef]

37. Gustavsson, M. Educational benefits from solar technology-Access to solar electric services and changes in children's study routines, experiences from eastern province Zambia. Energy Policy 2007, 35, 1292-1299. [CrossRef]

38. Steel, W.F.; Anyidoho, N.A.; Dadzie, F.Y.; Hosier, R.H. Developing rural markets for solar products: Lessons from Ghana. Energy Sustain. Dev. 2016, 31, 178-184. [CrossRef]

39. Diallo, A.; Moussa, R.K. The effects of solar home system on welfare in off-grid areas: Evidence from Côte d'Ivoire. Energy 2019, 194, 116835. [CrossRef] 
40. Kebede, K.Y.; Mitsufuji, T.; Choi, E.K. After-sales service and local presence: Key factors for solar energy innovations diffusion in developing countries. In Proceedings of the PICMET'14 Conference: Portland International Center for Management of Engineering and Technology; Infrastructure and Service Integration, Kanazawa, Japan, 27-31 July 2014; pp. 3124-3130. [CrossRef]

41. Duke, R.D.; Jacobson, A.; Kammen, D.M. Photovoltaic module quality in the Kenyan solar home systems market. Energy Policy 2002, 30, 477-499. [CrossRef]

42. Schelling, N.; Hasson, M.J.; Huong, S.L.; Nevarez, A.; Lu, W.-C.; Tierney, M.; Subramanian, L.; Schützeichel, H. SIMbaLink: Towards a sustainable and feasible solar rural electrification system. In Proceedings of the 4th ACM/IEEE International Conference on Information and Communication Technologies and Development, London, UK, 13-16 December 2010; pp. 1-10. [CrossRef]

43. Rolffs, P.; Ockwell, D.; Byrne, R. Beyond technology and finance: Pay-as-you-go sustainable energy access and theories of social change. Environ. Plan. A 2015, 47, 2609-2627. [CrossRef]

44. Lemaire, X. Off-grid electrification with solar home systems: The experience of a fee-for-service concession in South Africa. Energy Sustain. Dev. 2011, 15, 277-283. [CrossRef]

45. Gustavsson, M. With time comes increased loads-An analysis of solar home system use in Lundazi, Zambia. Renew. Energy 2007, 32, 796-813. [CrossRef]

46. Green, J.M.; Wilson, M.; Cawood, W. Maphephethe rural electrification (photovoltaic) programme: The constraints on the adoption of solar home systems. Dev. South. Afr. 2001, 18, 19-30. [CrossRef]

47. Diouf, B.; Pode, R.; Osei, R. Initiative for 100\% rural electrification in developing countries: Case study of Senegal. Energy Policy 2013, 59, 926-930. [CrossRef]

48. Opiyo, N.N. How basic access to electricity stimulates temporally increasing load demands by households in rural developing communities. Energy Sustain. Dev. 2020, 59, 97-106. [CrossRef]

49. Bisaga, I.; Parikh, P. To climb or not to climb? Investigating energy use behaviour among Solar Home System adopters through energy ladder and social practice lens. Energy Res. Soc. Sci. 2018, 44, 293-303. [CrossRef]

50. Zubi, G.; Fracastoro, G.V.; Lujano-Rojas, J.M.; El Bakari, K.; Andrews, D. The unlocked potential of solar home systems; an effective way to overcome domestic energy poverty in developing regions. Renew. Energy 2019, 132, 1425-1435. [CrossRef]

51. Urpelainen, J. Energy poverty and perceptions of solar power in marginalized communities: Survey evidence from Uttar Pradesh, India. Renew. Energy 2016, 85, 534-539. [CrossRef]

52. Winther, T.; Ulsrud, K.; Saini, A. Solar powered electricity access: Implications for women's empowerment in rural Kenya. Energy Res. Soc. Sci. 2018, 44, 61-74. [CrossRef]

53. Acker, R.H.; Kammen, D.M. The quiet (energy) revolution: Analysing the dissemination of photovoltaic power systems in Kenya. Energy Policy 1996, 24, 81-111. [CrossRef]

54. Schmitt, B.H. Customer Experience Management: A Revolutionary Approach to Connecting with Your Customers; John Wiley \& Sons, Inc.: Hoboken, NJ, USA, 2003.

55. Bisaga, I.; Puźniak-Holford, N.; Grealish, A.; Baker-Brian, C.; Parikh, P. Scalable off-grid energy services enabled by IoT: A case study of BBOXX SMART Solar. Energy Policy 2017, 109, 199-207. [CrossRef]

56. IEA. Access to Electricity Database 2020; IEA: Paris, France, 2020.

57. Koo, B.B.; Rysankova, D.; Portale, E.; Angelou, N.; Keller, S.; Padam, G. Rwanda: Beyond Connections; ESMAP: Washington, DC, USA, 2018.

58. Commonwealth Local Government Forum. The local government system in Rwanda; Commonwealth Local Government Forum: London, UK, 2018.

59. NISR; MINECOFIN. Fourth Rwanda Population and Housing Census: Atlas; NISR: Kigali, Rwanda, 2012.

60. NISR; MINECOFIN. Thematic Report: Population Size, Structure and Distribution; NISR: Kigali, Rwanda, 2014.

61. Feron, S. Sustainability of Off-Grid Photovoltaic Systems for Rural Electrification in Developing Countries: A Review. Sustainability 2016, 8, 1326. [CrossRef]

62. De Schrijver, A. Sample survey on sensitive topics: Investigating respondents' understanding and trust in alternative versions of the randomized response technique. J. Res. Pract. 2012, 8, 1-17.

63. Power Africa. Off-Grid Solar Market Assessment Rwanda; Power Africa: Washington, DC, USA, 2019.

64. NISR. Labour Force Survey Annual Report 2019; NISR: Kigali, Rwanda, 2020.

65. NISR. Unlocking Rwanda's Potential to Reap the Demographic Dividend; NISR: Kigali, Rwanda, 2017.

66. Rwanda Utilities Regulatory Authority. Statistics Report for Telecom, Media and Broadcasting Sector as of the First Quarter of the Year 2020; Rwanda Utilities Regulatory Authority: Kigali, Rwanda, 2020.

67. Rwanda Utilities Regulatory Authority. Statistics Report for Telecom, Media and Broadcasting Sector as of the Third Quarter of the Year 2017; Rwanda Utilities Regulatory Authority: Kigali, Rwanda, 2017.

68. Urpelainen, J.; Yoon, S. Solar home systems for rural India: Survey evidence on awareness and willingness to pay from Uttar Pradesh. Energy Sustain. Dev. 2015, 24, 70-78. [CrossRef]

69. Khan, I. Impacts of energy decentralization viewed through the lens of the energy cultures framework: Solar home systems in the developing economies. Renew. Sustain. Energy Rev. 2020, 119, 109576. [CrossRef]

70. Scott, I. A business model for success: Enterprises serving the base of the pyramid with off-grid solar lighting. Renew. Sustain. Energy Rev. 2017, 70, 50-55. [CrossRef] 
71. Brunet, C.; Savadogo, O.; Baptiste, P.; Bouchard, M.A. Shedding some light on photovoltaic solar energy in Africa-A literature review. Renew. Sustain. Energy Rev. 2018, 96, 325-342. [CrossRef]

72. Grimm, M.; Munyehirwe, A.; Peters, J.; Sievert, M. A first step up the energy ladder? Low cost solar kits and household's welfare in rural Rwanda. World Bank Econ. Rev. 2017, 31, 631-649. [CrossRef]

73. Gebreslassie, M.G. Solar home systems in Ethiopia: Sustainability challenges and policy directions. Sustain. Energy Technol. Assess. 2020, 42, 100880. [CrossRef]

74. Wamukonya, N.; Davis, M. Socio-economic impacts of rural electrification in Namibia: Comparisons between grid, solar and unelectrified households. Energy Sustain. Dev. 2001, 5, 5-13. [CrossRef]

75. Azimoh, C.L.; Wallin, F.; Klintenberg, P.; Karlsson, B. An assessment of unforeseen losses resulting from inappropriate use of solar home systems in South Africa. Appl. Energy 2014, 136, 336-346. [CrossRef]

76. Brown, E.; Leary, J.; Davies, G.; Batchelor, S.; Scott, N. eCook: What behavioural challenges await this potentially transformative concept? Sustain. Energy Technol. Assess. 2017, 22, 106-115. [CrossRef]

77. Wirtz, J.; Tang, C.; Georgi, D. Successful referral behavior in referral reward programs. J. Serv. Manag. 2019, 30, 48-74. [CrossRef]

78. William, M.C. Positive Versus Negative Word-of-mouth: Effects on Receivers. Acad. Mark. Stud. J. 2017, 21, 1-10.

79. Choumert-Nkolo, J.; Combes Motel, P.; Le Roux, L. Stacking up the ladder: A panel data analysis of Tanzanian household energy choices. World Dev. 2019, 115, 222-235. [CrossRef]

80. Zubi, G.; Spertino, F.; Carvalho, M.; Adhikari, R.S.; Khatib, T. Development and assessment of a solar home system to cover cooking and lighting needs in developing regions as a better alternative for existing practices. Sol. Energy 2017, 155, 7-17. [CrossRef] 